\title{
The transcriptional response of neurotrophins and their tyrosine kinase receptors in lumbar sensorimotor circuits to spinal cord contusion is affected by injury severity and survival time
}

\author{
M. Tyler Hougland ${ }^{1,2}$, Benjamin J. Harrison ${ }^{1,2}$, David S. K. Magnuson ${ }^{1,3}$, Eric C. Rouchka ${ }^{4,5}$ and \\ Jeffrey C. Petruska ${ }^{1,2 *}$ \\ ${ }^{1}$ Department of Anatomical Sciences and Neurobiology, University of Louisville, Louisville, KY, USA \\ ${ }^{2}$ Laboratory of Neural Physiology and Plasticity, Kentucky Spinal Cord Injury Research Center, Department of Neurological Surgery, Louisville, KY, USA \\ ${ }^{3}$ Laboratory of Locomotor Systems and Rehabilitation, Kentucky Spinal Cord Injury Research Center, Department of Neurological Surgery, Louisville, KY, USA \\ ${ }^{4}$ Department of Computer Engineering and Computer Science, University of Louisville, Louisville, KY, USA \\ ${ }^{5}$ Laboratory of Bioinformatics, Department of Computer Engineering and Computer Science, Louisville, KY, USA
}

Edited by:

Alexander Rabchevsky, University of Kentucky, USA

Reviewed by:

Arthur Brown, University of Western

Ontario, Canada

Marion Murray, Drexel University

College of Medicine, USA

*Correspondence:

Jeffrey C. Petruska, Department of

Anatomical Sciences and

Neurobiology, 500 South Preston

Street, University of Louisville,

Louisville, KY 40292, USA.

e-mail: j.petruska@louisville.edu
Traumatic spinal cord injury (SCl) results in changes to the anatomical, neurochemical, and physiological properties of cells in the central and peripheral nervous system. Neurotrophins, acting by binding to their cognate Trk receptors on target cell membranes, contribute to modulation of anatomical, neurochemical, and physiological properties of neurons in sensorimotor circuits in both the intact and injured spinal cord. Neurotrophin signaling is associated with many post-SCl changes including maladaptive plasticity leading to pain and autonomic dysreflexia, but also therapeutic approaches such as training-induced locomotor improvement. Here we characterize expression of mRNA for neurotrophins and Trk receptors in lumbar dorsal root ganglia (DRG) and spinal cord after two different severities of mid-thoracic injury and at 6 and 12 weeks post-SCl. There was complex regulation that differed with tissue, injury severity, and survival time, including reversals of regulation between 6 and 12 weeks, and the data suggest that natural regulation of neurotrophins in the spinal cord may continue for months after birth. Our assessments determined that a coordination of gene expression emerged at the 12-week post-SCl time point and bioinformatic analyses address possible mechanisms. These data can inform studies meant to determine the role of the neurotrophin signaling system in post-SCl function and plasticity, and studies using this signaling system as a therapeutic approach.

Keywords: spinal cord injury, neurotrophins, neurotrophin receptors, contusions, transcription, injury mechanisms, sensory neurons, genetic regulation

\section{INTRODUCTION}

Traumatic injury to the spinal cord (SC) results in a variety of changes to sensorimotor circuits. Sensory neurons of the dorsal root ganglia (DRG) rapidly undergo long-lasting changes in their electrophysiological properties and growth capacity (e.g., Bedi et al., 2010, 2012; Walters, 2012). Locomotor circuitry in the SC caudal to an injury site undergoes plasticity at the cellular, synaptic, and connectivity levels in an activity-dependent manner after injury in humans and experimental models (e.g., Edgerton et al., 2004; Rossignol, 2006; Petruska et al., 2007). One strategy to restore function after spinal cord injury (SCI) is physical therapy and/or locomotor rehabilitation training (e.g., Wernig et al., 1995). The neurotrophins Nerve Growth Factor (NGF), Brain Derived Neurotrophic Factor (BDNF), and Neurotrophin 3 (NT3) are secreted growth factors that were first characterized for their important role in the survival of subpopulations of sensory neurons and in formation of SC sensorimotor circuits during development (e.g., Barbacid, 1995; Lindsay, 1996; Huang and Reichardt, 2001). In addition to these essential roles in establishing the physiological patterns of developing neural circuitry, neurotrophins are implicated as having a role in activity-dependent changes associated with restoration of function after SCI (described below).

Neurotrophins have key roles in modulating the anatomical, neurochemical, and physiological properties of cells in the central and peripheral nervous system. The effects of neurotrophins on responses to stimuli in both the intact and injured nervous system have been extensively investigated and studies have demonstrated an important role in modulation of sensorimotor physiology (for reviews, see Huang and Reichardt, 2001, 2003; Reichardt, 2006; Skaper, 2008, 2012). The neurotrophins have therefore become a frequent target for manipulation after injury. Delivery of exogenous BDNF and NT3 to the transected SC improves recovery of hindlimb function (Blits et al., 2003; in rats) and results in a level of function similar to that seen in animals receiving locomotor training after spinal transection (Boyce et al., 2007; in cats). Such demonstrations of enhanced post-SCI function in response to exogenous neurotrophins suggests a role for neurotrophin signaling in models of activity-dependent plasticity after injury, possibly 
including physical therapy. For example, in the lumbar SC of rats, post-SCI locomotor training causes an increase in both BDNF and NT3 above levels of non-trained animals (Hutchinson et al., 2004; Côté et al., 2011). In light of the demonstrated and suggested roles in modulating sensorimotor physiology, characterizing the endogenous regulation of neurotrophins and their receptors after injury is particularly relevant.

Neurotrophins influence cellular processes by binding to membrane-bound receptors which transduce the extracellular signal into intracellular effect - their high affinity tyrosine kinase receptors. In general, NGF binds TrkA, BDNF bindsTrkB, and NT3 binds TrkC (e.g., Barbacid, 1995; Patapoutian and Reichardt, 2001; Huang and Reichardt, 2003), although cross-talk is recognized and there is a low-affinity receptor, p75, which we do not consider here. To determine the role of neurotrophins in any process or condition one must examine not only the neurotrophins, but also the receptors.

Prior characterizations of changes in neurotrophins and Trk receptors in lumbar neural circuitry have been instrumental in elucidating the complex regulation of these important molecules after injury (Table 1). However, these have largely focused on time points of less than 6 weeks (Hayashi et al., 2000; Liebl et al., 2001; Nakamura and Bregman, 2001; Widenfalk et al., 2001; Qiao and Vizzard, 2002, 2005; Gulino et al., 2004; Zvarova et al., 2004; Qin et al., 2006; Li et al., 2007; Hajebrahimi et al., 2008; Qian et al., 2011; Keeler et al., 2012). Although valuable for elucidating the role of neurotrophin signaling in the first 6 weeks after SCI, these data are of uncertain value for relating to longer-term post-SCI function. Given the many demonstrations of continued changing conditions after SCI (e.g., Beattie et al., 2002; Profyris et al., 2004; Ung et al., 2008; Beck et al., 2010), it is important to recognize that the temporal character of experiments has a significant influence on the outcome.

The impact of SCI also varies depending on the location of the injury itself and the spatial relation of the investigated tissue to the SCI. Clearly, the relative composition of types of tissues innervated changes throughout the course of the neuraxis as does the specific function of local circuitry. For example, in rat, the spinal components of bladder control are focused on the T13/L1 and L6/S1 segments, colon function is focused in L6/S1, and the locomotor central pattern generator appears focused in (though not limited to) the L1/2 segments, spinal sympathetic circuitry regulating outflow exists roughly from T1-L2, and spinal parasympathetic circuitry exists in the sacral-caudal SC. Thus it follows that the effect on spared function and/or recovery is influenced by the level of the injury (e.g., Magnuson et al., 1999, 2005; Garcia-Alias et al., 2006), but this also extends to less direct functions (Campagnolo et al., 2000; Lucin et al., 2007). It is also very important to consider that both neural and non-neural tissues remote from the SCI can be affected (e.g., Collazos-Castro et al., 2005; Massey et al., 2006; Gris et al., 2008).

Sensory input to the SC plays a role in establishing natural and therapy-induced recovery and regulating spinal function in the absence of descending control. For example, urinary bladder function after SCI is highly reliant on sensory input and plasticity of sensory afferents (e.g., Tai et al., 2006; de Groat and Yoshimura, 2009), and SCI affects the trk receptor profile of neurons in DRG segments innervating bladder differently than for DRG innervating hindlimb (Qiao and Vizzard, 2002, 2005), a finding that extends to spinal trk receptors as well (Zvarova et al., 2004). Additionally, the type and amount of sensory input can influence spontaneous recovery after SCI (e.g., Grau et al., 2004, 2012; Ollivier-Lanvin et al., 2010; Caudle et al., 2011; Ferguson et al., 2012a,b) and also influence the effectiveness of physical therapy (e.g., Bouyer and Rossignol, 1998, 2003; Edgerton et al., 2004, 2008; GomezPinilla et al., 2004; Frigon and Rossignol, 2009; Ollivier-Lanvin et al., 2010), all of which may involve neurotrophin signaling (e.g., Gomez-Pinilla et al., 2004; Hutchinson et al., 2004; Boyce et al., 2007, 2012; de Leon, 2007; Côté et al., 2011). Further, autonomic dysreflexia $(\mathrm{AD})$, a life-threatening condition that is common for those living long-term with cervical or high thoracic SCI, is triggered most frequently by nociceptive sensory input (Maiorov et al., 1998; Krassioukov and Fehlings, 1999; Garstang and Miller-Smith, 2007), and sprouting of central terminals of nociceptive neurons, purportedly modulated by NGF, is proposed as a mechanism contributing to AD (Weaver et al., 1997; Krenz et al., 1999; Marsh et al., 2002; Cameron et al., 2006; Ackery et al., 2007). It is important, therefore, to examine not only the SC, but also the sensory neurons providing information to the SC, and to consider that the effects of SCI on these neurons may differ with their spatial relation to the SCI, and/or to the different tissues they innervate (e.g., Qiao and Vizzard, 2002; Zvarova et al., 2004; Bedi et al., 2010, 2012; Keeler et al., 2012). The spatial character of experiments, in terms both of the level of SCI and the relation to the SCI of the tissue investigated, has a significant influence on the outcome.

Injury severity, or more precisely the degree and nature of the tissue spared after injury, is one of the key factors determining the functional capabilities of the SC caudal to the SCI. The literature is replete with examples of this when reports are considered together (e.g., Rossignol and Frigon, 2011). Far fewer single studies examine multiple injury severities (e.g., Magnuson et al., 2005; Smith et al., 2006), although the injury severity character of experiments has a significant influence on the outcome.

We sought to characterize the natural regulation of neurotrophin and trk receptor genes in tissues and conditions that were applicable to experimental studies of long-term function and recovery after SCI and to the human condition. We therefore characterized the transcriptional response of neurotrophins and their cognate Trk receptors to SC contusion temporally ( 6 and 12 weeks post injury), spatially (in lumbar SC and DRG), and relative to injury severity (12.5 and $25 \mathrm{~g} \mathrm{~cm} \mathrm{NYU} \mathrm{contusions).}$

\section{MATERIALS AND METHODS}

All experimental protocols and procedures were approved by the Institutional Animal Care and Use Committee at the University of Louisville, Louisville, KY, USA. Experimental animals were 7 week old female Sprague-Dawley rats (Taconic Labs, Hudson, NY, USA). Animals were housed in pairs throughout the course of our experiments.

\section{SURGICAL SPINAL CORD INJURY}

Rats $(n=47)$ were anesthetized with $50 \mathrm{mg} / \mathrm{kg}$ sodium pentobarbital (Sigma, St Louis, MO, USA). Once sedated, Lacquer Lube was applied to the eyes to prevent drying. After skin incision, 


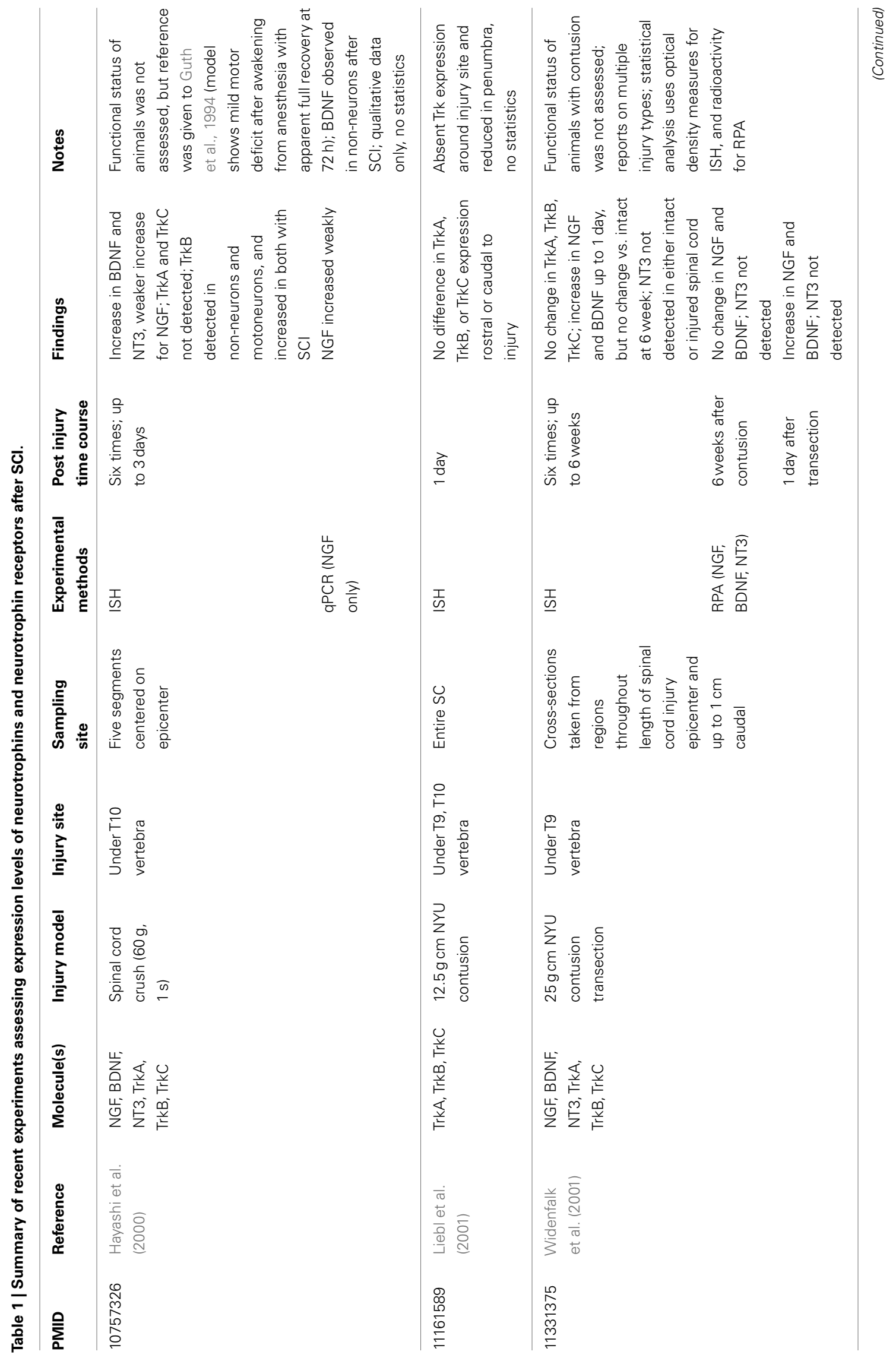


Hougland et al.

Post-SCI transcriptional regulation of neurotrophins/Trks

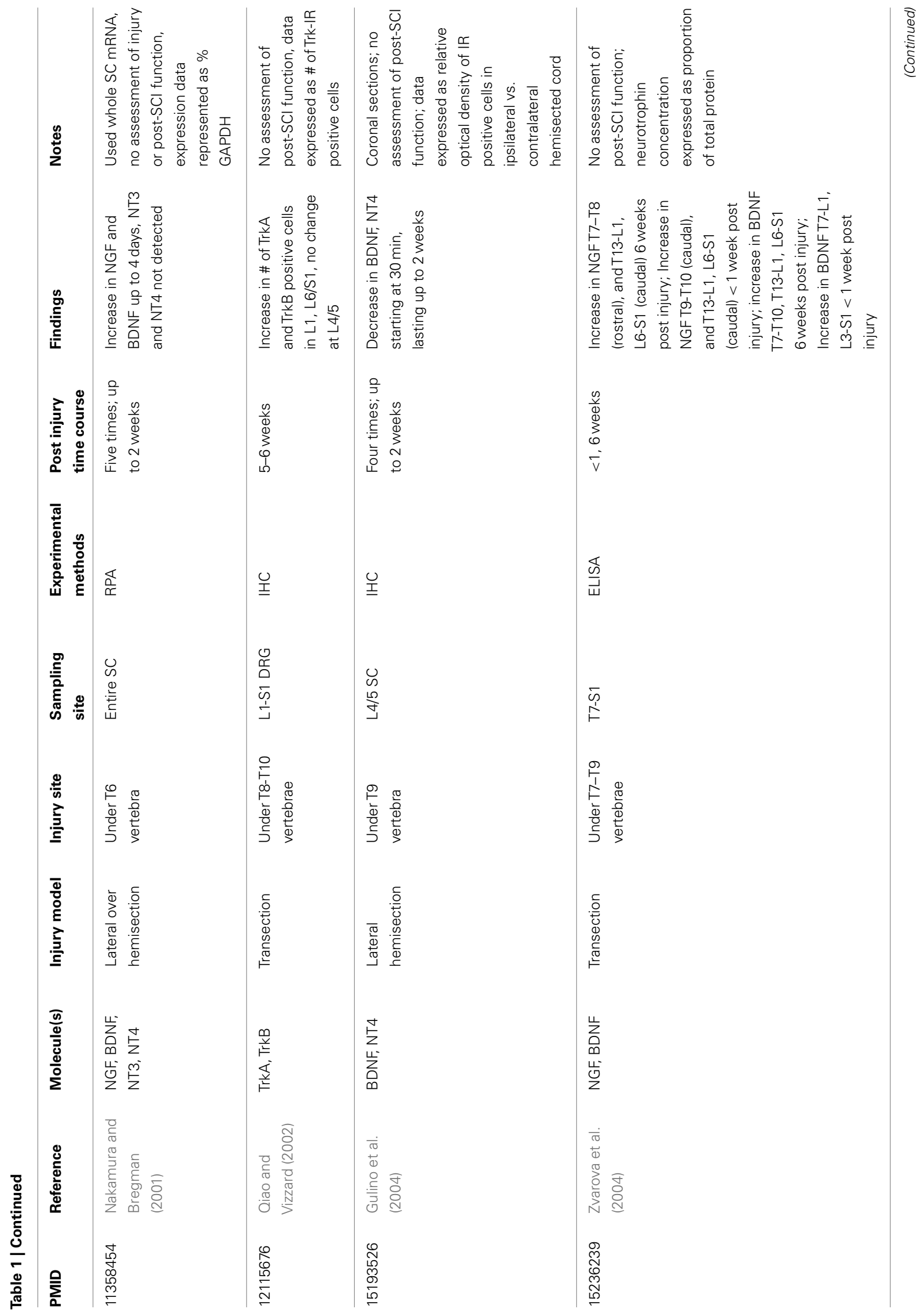

Frontiers in Physiology | Integrative Physiology

January 2013 | Volume 3 | Article 478 | 4 


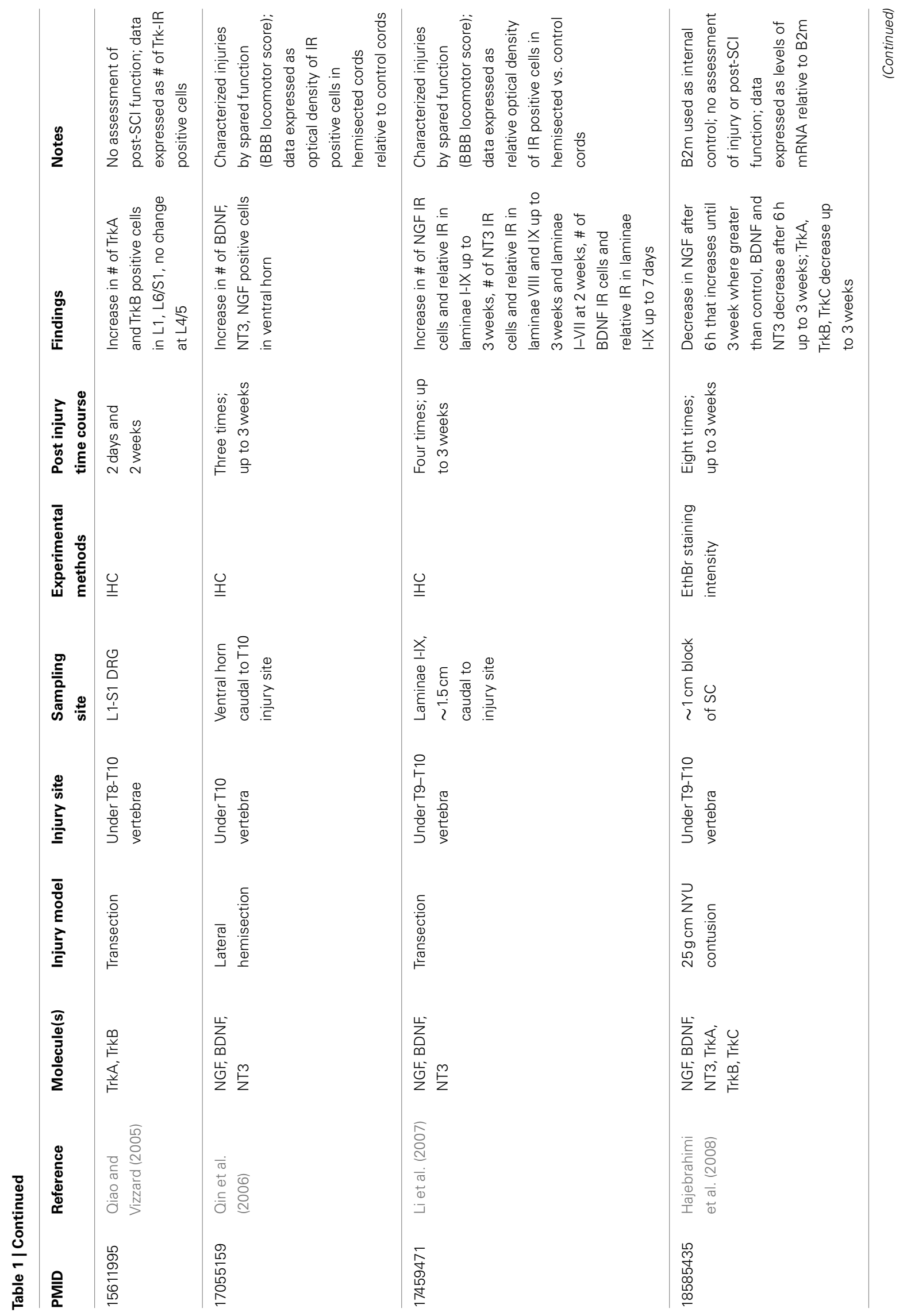




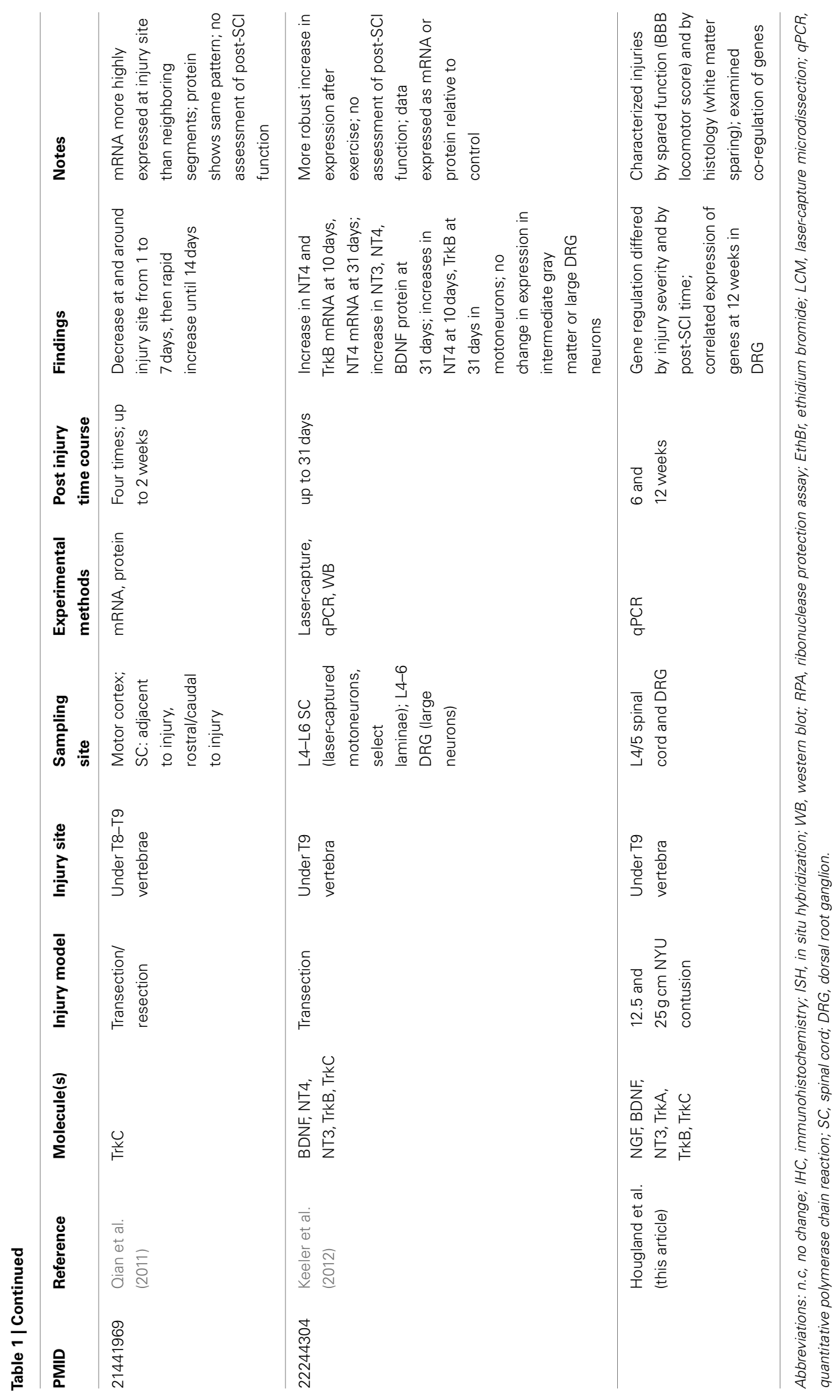


laminectomy was performed at vertebral level T9, to expose the T10 SC. Contusion injuries were produced using the New York University (NYU) Impactor. Either "Moderate" or "Moderately severe" injuries were produced by releasing a $10 \mathrm{~g}, 2 \mathrm{~mm}$ rod from 12.5 or $25 \mathrm{~mm}$ height, respectively, onto the exposed dura mater of the SC. These will subsequently be referred to as 12.5 and $25 \mathrm{~g} \mathrm{~cm}$ injuries. After producing the contusion the wound was closed in layers and the skin incision was stapled. Rats received fluids (10cc $0.9 \%$ saline subcutaneously), and antibiotic treatment ( $0.1 \mathrm{cc}$ Gentamicin $(50 \mathrm{mg} / \mathrm{mL})$ intramuscularly, and Bacitracin was topically applied on the incision site). Animals were housed overnight in a recovery room with a heating pad under their cage, and were taken to the animal facilities in the morning.

Assessment of mRNA expression in SCI animals was compared to control animals. These consisted of naïve rats (two per time point group) and rats receiving laminectomy-only (three rats per time point group), for a total of five controls per time point. There were four additional laminectomy-only control rats included with the animals used for the 6-week post-SCI DRG assessment. All surgical procedures (except for the SCI), were as described above for the laminectomy-only control rats.

\section{INJURY CHARACTERIZATION Behavior}

Experiments were performed on rats separated into groups based on injury severity, survival time, and the tissue to be analyzed for mRNA expression. Rats were familiarized with the testing procedures and personnel by handling for 1 week before injury. Pre-surgical behavioral assessments were done to ensure no pre-existing conditions were present that would subsequently affect our locomotor outcome measures. Seventeen rats received $12.5 \mathrm{~g} \mathrm{~cm}$ NYU (moderate) and 16 rats received $25 \mathrm{~g} \mathrm{~cm} \mathrm{NYU}$ (moderately severe) injuries. Hindlimb locomotor function was assessed with the Basso, Beattie, and Bresnahan (BBB) Locomotor Rating Scale (Basso et al., 1996). BBB testing was carried out prior to injury and 7, 14, 21, 28, 35, 42 for the 6-week SC group, and 7, 14, $21,28,35,42,49,56,63,72,79$, and 84 days post injury for the 12 week SC groups, 12 week DRG group, and at 7, 14, 28, and 42 days post injury for the 6-week DRG group. For testing, rats were placed in an open field (a plastic tank that was $105 \mathrm{~cm}$ in diameter with $30 \mathrm{~cm}$ high walls) for $4 \mathrm{~min}$. BBB testing was done after animal care in the morning. Hindlimb movement and locomotion were scored simultaneously by two observers who were blind to the treatment groups. We include the BBB measures as a means to characterize the injuries with commonly used assessments so that the mRNA measures can be placed in context.

\section{Histology}

At the end of the testing period, rats were anesthetized with sodium pentobarbital and euthanized via transcardial perfusion with $30 \%$ RNA Later (Qiagen) in 0.1 M Phosphate Buffered Saline (PBS). An approximately $10 \mathrm{~mm}$ long block of SC containing the injury epicenter was removed from each animal and immersed in $4 \%$ paraformaldehyde. After 1 week cords were immersed in PBS containing 30\% sucrose for cryoprotection until further processing. For sectioning, tissue was embedded in TissueTek ${ }^{\circledR}(\mathrm{VWR})$ and frozen. The blocks were cut $50 \mu \mathrm{m}$ thick in the transverse plane on a cryostat and were sampled every $250 \mu \mathrm{m}$. A series of sections spanning the rostrocaudal extent of the lesion was stained with eriochrome cyanine (EC) to assess amounts of spared myelin as described (Rabchevsky et al., 2007). Light microscopy was used to determine spared white matter (SWM). Images were captured using a SPOT digital camera (Diagnostic Instruments) mounted on a Zeiss Axioskop. From these, the area of spared tissue was manually designated (Intuos drawing tablet; Wacom, Otone, Japan). Areas of white matter sparing were calculated using the ImageJ program and expressed as a proportion of control (defined as group mean of the smallest white matter area from an analogous section of SC from all control animals). For each injured animal, the SCI epicenter was defined quantitatively as the section containing the least amount of intact tissue. Percent white matter sparing is reported as mean $( \pm \mathrm{SD})$. As with the $\mathrm{BBB}$, we include the WMS measures as a means to characterize the injuries with commonly used assessments so that the mRNA measures can be placed in context.

\section{MRNA EXPRESSION \\ Isolation and cDNA conversion}

Animals were euthanized after final behavioral assessments and exsanguinated by transcardial perfusion using 30\% RNA later (Qiagen) in PBS. Lumbar SCs (L4/5) and DRG were removed and immersed in $100 \%$ RNA later and stored at $-20^{\circ} \mathrm{C}$ until further processing. SCs were homogenized on ice in $1 \mathrm{~mL}$ Trizol and RNA was isolated using Trizol/chloroform extraction method. Briefly, homogenate was transferred to a $1.5 \mathrm{~mL}$ tube and spun at $12,000 \mathrm{~g}$ for $10 \mathrm{~min}$ at $2^{\circ} \mathrm{C}$. The supernatant was transferred to a new tube and $200 \mu \mathrm{L}$ chloroform added. This mixture was spun for $15 \mathrm{~min}$ at $2^{\circ} \mathrm{C}$ to separate into aqueous and organic phases. The aqueous phase was transferred to a new tube and alcohol precipitation was performed with $100 \%$ isopropanol, then $70 \%$ ethanol. After removal and drying of excess ethanol, the pellet was resuspended in $30 \mu \mathrm{L}$ nuclease free $\mathrm{H}_{2} 0$, solubilized in $600 \mu \mathrm{L}$ Buffer RLT with beta-Mercaptoethanol (BME), and processed through RNeasy MiniKit (Qiagen) per manufacturers protocol. DRGs were homogenized directly in Buffer RLT + BME and processed through RNeasy MiniKit. RNA was analyzed by Nanodrop (ThermoScientific, Waltham, MA, USA) to obtain concentration and $500 \mathrm{ng}$ of RNA from each sample was reverse transcribed into cDNA using Quanta Biosciences qScript cDNA SuperMix. All RNA was converted to cDNA using the same lot of reverse transcriptase. Performing the reverse-transcription for all samples with the same reagents is a methodological procedure meant to reduce the cross-sample variability which in turn can enhance the reliability of statistical assessments.

\section{qRT-PCR}

mRNA expression levels were quantified by qRT-PCR on Corbett Research 6000 (Qiagen) using FastStart Universal SYBR Green Master Mix(Roche). Duplicate reactions were run for each sample for both the gene of interest and the normalizer [Beta-3 Tubulin demonstrated as a suitable normalizer gene for SCI work (Strube et al., 2008)]. Relative expression levels were calculated as $\Delta \Delta \mathrm{CT}$ of gene of interest vs. normalizer. Primer sequences for the genes 
analyzed are provided in Table 2, along with their relationship to the known gene structure and transcript species.

\section{STATISTICS}

Statistical analyses were performed using SPSS (IBM, North Castle, NY, USA) or SigmaPlot/SigmaStat (Systat Software, San Jose, CA, USA). A Student's $t$-test was performed to determine if expression levels differed between control groups. In cases where gene expression did not differ between control groups the 6- and 12-week control groups were combined and the expression values for the experimental groups are reported as a fold-change of the unified control group. One-way analysis of variance (ANOVA) was performed on these values with post hoc Tukey's test for all pairwise comparisons. All groups with $p<0.05$ difference are reported as significant. Pearson Product Moment was calculated to determine the relationships between the expression levels of the different transcripts, and to determine the relationships between BBB/WMS vs. expression levels. Differences between BBB scores were assessed using a mixed model repeated measures ANOVA with a post hoc Bonferroni $t$-test.

\section{RESULTS}

\section{INJURY CHARACTERIZATION}

To assess the degree of injury severity, we characterized SC injuries based on two parameters; behavior as measured by BBB, and the amount of SWM at the epicenter after staining with eriochrome cyanin (Rabchevsky et al., 2007). BBB scores were significantly greater in the $12.5 \mathrm{~g} \mathrm{~cm}$ injury groups than the $25 \mathrm{~g} \mathrm{~cm}$ groups beginning at week 5 (Figure 1A). These differences in behavior were reflected in the amount of SWM, as the $25 \mathrm{~g} \mathrm{~cm}$ groups had $8.5 \%( \pm 1.8 \%)$ and the $12.5 \mathrm{~g} \mathrm{~cm}$ groups had $13.9 \%( \pm 3.6 \%)$ SWM at the epicenter. In accord with prior literature (Basso et al., 1996; Schucht et al., 2002; Magnuson et al., 2005), a significant correlation ( $r=0.88, p<0.001)$ was observed between white matter sparing at epicenter and BBB scores (Figure 1B). BBB scores of the $12.5 \mathrm{~g} \mathrm{~cm}$ group showed a high degree of variability and continued to increase between 6 and 12 weeks instead of reaching a plateau. Within this group, two animals had BBB scores consistent with the range observed in previous literature (Basso et al., 1996; Agrawal et al., 2010; 12 and 13) and four animals that had higher BBB scores than expected for this injury severity (mean 17.9) at 12 weeks post injury. We considered that these results may be due to both greater amount of SWM and/or asymmetry of the lesion (Figures 1C,D). Indeed, of the four animals whose BBB scores continued to increase, all had a greater amount of SWM (mean $16.1 \%$ for four animals with higher BBB scores, $10.1 \%$ for two animals with lower BBB scores), and all had asymmetrical injuries (arbitrarily defined as more than $4 \%$ greater SWM on one side vs. the other). Animals with the lower BBB scores in the $12.5 \mathrm{~g} \mathrm{~cm}$ group did not represent statistical outliers (Grubbs outlier test). Separate statistical analyses of gene expression were performed with the exclusion of the two animals whose BBB scores did not continue to increase and the results generally did not differ from those found when all six animals were considered together. The lone exception was the results for expression of one Trk receptor in the SC, which is noted below. We thus consider all six animals

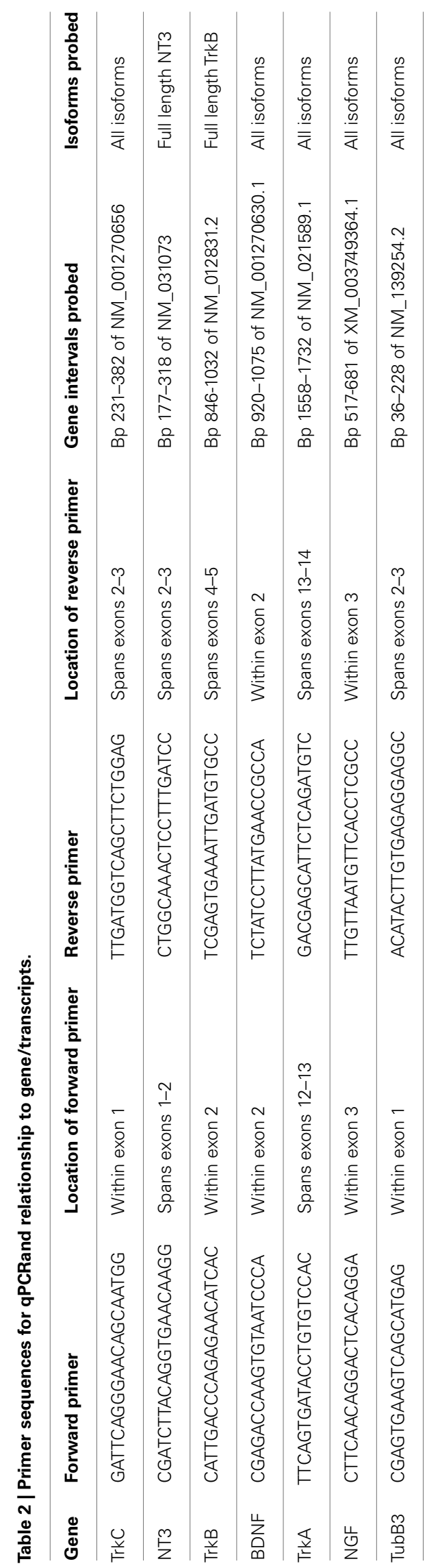



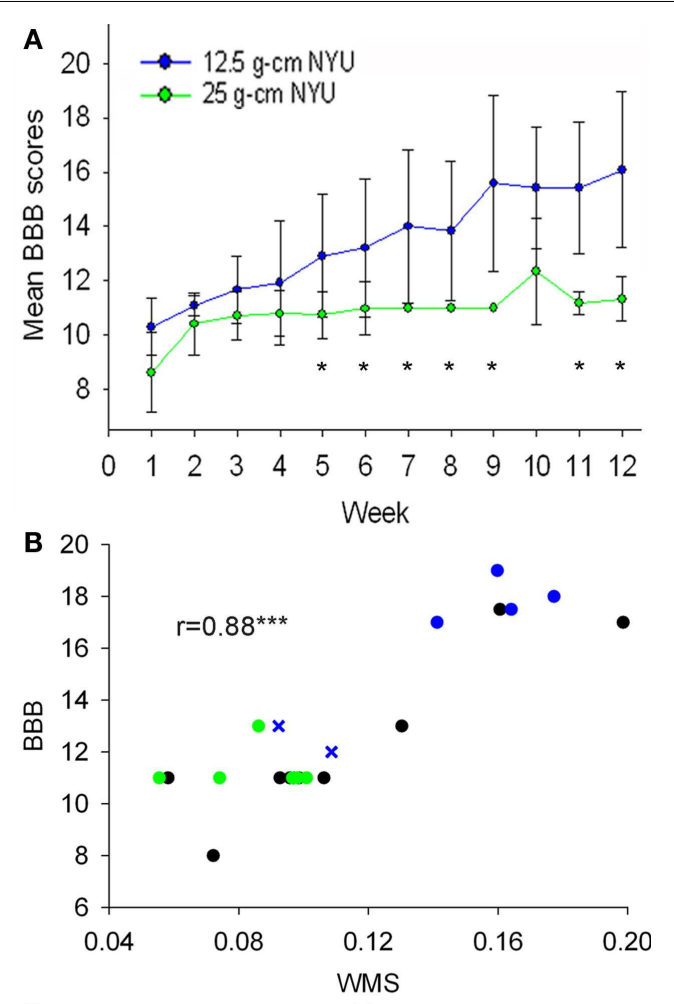

C

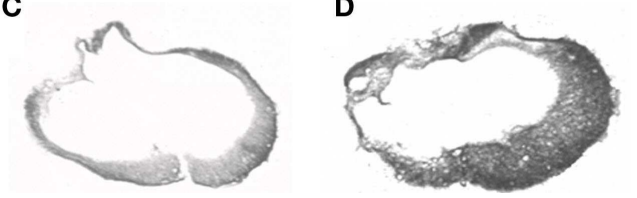

FIGURE 1 | Injuries were characterized using BBB scores to assess hindlimb locomotor function and white matter sparing (WMS) at epicenter using EC stain. (A) BBB scores of groups that received $12.5 \mathrm{~g} \mathrm{~cm}$ (blue) or $25 \mathrm{~g} \mathrm{~cm}$ (green) NYU injuries. Starting at week 5, a significant difference was observed between the two injury severities. Both groups were significantly different $(p<0.05)$ from controls (not shown) at all time points. (B) White matter sparing at epicenter ( $x$ axis) plotted vs. BBB score. Black dots represent 6 week values. Green dots represent 12 week, $25 \mathrm{~g} \mathrm{~cm}$ injured animals. Blue $x$ represent the two animals from the 12 -week, $12.5 \mathrm{~g} \mathrm{~cm}$ group with the lowest BBB scores within the group. Blue dots represent the four animals from the 12 -week, $12.5 \mathrm{~g} \mathrm{~cm}$ group with the highest BBB scores within the group. (C) Image taken from a $12.5 \mathrm{~g} \mathrm{~cm}$ contused animal showing a laterally-symmetrical injury pattern at the epicenter. Note the difference from (D), which was taken from an animal that also received a $12.5 \mathrm{~g} \mathrm{~cm}$ spinal cord contusion but which yielded an asymmetrical injury at epicenter. ${ }^{*} p<0.05,{ }^{* * *} p<0.001$.

together in the group in all subsequent figures and analyses of mRNA expression.

\section{EXPRESSION OF Trk RECEPTORS IN THE DRG}

One purpose of this study was to determine whether these different contusion severities result in a differential transcriptional response of neurotrophins and their Trk receptors in lumbar sensorimotor circuits. Hence, we sought to determine the expression level of Trk receptors in the DRG 6 and 12 weeks after our two severities of contusion injury. Expression of TrkA, TrkB, and TrkC each differed significantly between the 6- and 12-week groups, with the magnitude and direction of difference depending on receptor type and injury severity. Expression of TrkA mRNA in DRG from the 12-week group at both injury severities was significantly greater than that in DRG from the corresponding 6 week group. Expression of TrkA in DRG from the 12-week group that received $12.5 \mathrm{~g} \mathrm{~cm}$ injury was also elevated relative to the control groups. We also observed a difference in TrkA expression between injury severities at the 12 -week time point. Similar to TrkA, expression of TrkC mRNA in DRG from the 12-week group was greater than that in DRG from the corresponding 6 week group at both injury severities, but the difference only reached significance in the $12.5 \mathrm{~g} \mathrm{~cm}$ animals. Unlike the findings for TrkA, we detected no significant difference in TrkC expression between DRG from the $12.5 \mathrm{~g} \mathrm{~cm}$ group and from the $25 \mathrm{~g} \mathrm{~cm}$ group at the 12 week time point. Expression of mRNA for TrkB in DRG at 12 weeks after $25 \mathrm{~g} \mathrm{~cm}$ injury was significantly lower than in DRG from both the 6-week SCI and control groups. No significant difference in TrkB expression was observed between injury severities at 6 or 12 week time points in the $12.5 \mathrm{~g} \mathrm{~cm}$ injury group (Figure 2 ).

\section{EXPRESSION OF NEUROTROPHINS IN THE DRG}

As with TrkA, NGF mRNA expression in DRG from the $12.5 \mathrm{~g} \mathrm{~cm}$ injury severity group was significantly greater in the 12 -week group than in both the 6-week and control groups. However, no significant changes in NGF expression were observed between survival time groups in the $25 \mathrm{~g} \mathrm{~cm}$ injury severity group. As with TrkB, BDNF expression in the 12-week $25 \mathrm{~g} \mathrm{~cm}$ group was significantly less than in the 6 -week $25 \mathrm{~g} \mathrm{~cm}$ group, but did not differ from the control group (Figure 3). No other differences were observed in BDNF expression levels. There was a large increase in the mean expression of NT3 in DRG from the 12 -week, $12.5 \mathrm{~g} \mathrm{~cm}$ injury group, however due to high variance no significant differences were observed from 6 to 12 weeks.

\section{EXPRESSION OF Trk RECEPTORS IN THE SPINAL CORD}

Expression levels of mRNA for neurotrophin receptors TrkA, TrkB, and TrkC were assessed from samples of lumbar SC (L4/5). In the groups that received a $12.5 \mathrm{~g} \mathrm{~cm}$ injury, the level of TrkA in SC from the 12-week group was significantly greater than that from the 6week group, whereas there was no significant difference between the two post-SCI times in the $25 \mathrm{~g} \mathrm{~cm}$ injury group. Like TrkA, the level of TrkC in SC from the 12-week $12.5 \mathrm{~g} \mathrm{~cm}$ group was significantly greater than that from the 6-week group, with no significant difference between the two post-SCI times in the $25 \mathrm{~g} \mathrm{~cm}$ injury group. No significant changes in TrkB expression levels were detected between any groups (Figure 4).

\section{EXPRESSION OF NEUROTROPHINS IN THE SPINAL CORD}

The results for neurotrophins in the SC are displayed differently from the data regarding expression levels of neurotrophins and Trk receptors in the DRG, and Trk receptors in the SC. In the latter assessments, the expression of neurotrophins and trks did not differ between the 6- and 12-week control animals. Thus, those data were analyzed and presented relative to the mean and variation of a single unified control group. This allowed us to simultaneously assess the effect of both injury severity and survival time on gene 

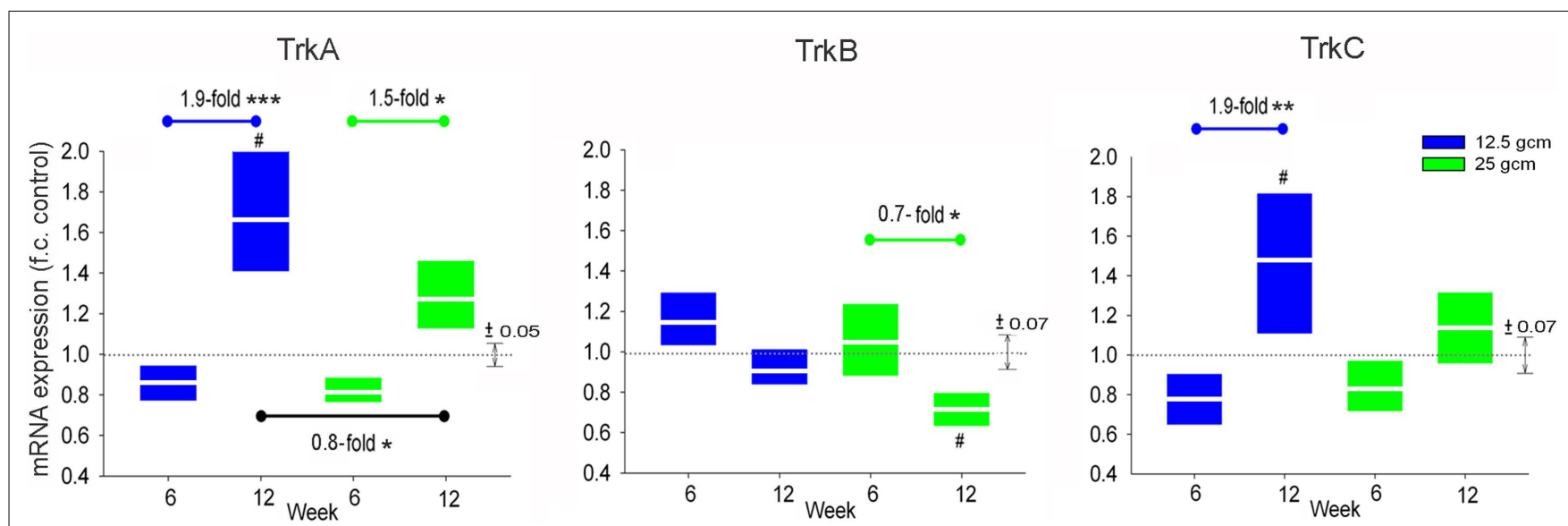

FIGURE 2 | mRNA expression of Trk receptors is altered in L4/5 DRG at 6 and 12 weeks after receiving either $12.5 \mathrm{~g} \mathrm{~cm}$ (blue) or $25 \mathrm{~g} \mathrm{~cm}$ (green) NYU contusion injury to spinal cord at vertebral level T9. Fold-change (FC) is reported as change of 12 week relative to 6 week time points in all figures. Black bar on TrkA reports fold-change ( $\mathrm{fc}$ ) of $25 \mathrm{~g} \mathrm{~cm}$ at 12 weeks relative to

$12.5 \mathrm{~g} \mathrm{~cm}$ at 12 weeks. $X$ axis denotes weeks post injury. White lines in box-plots indicate group mean. Dotted gray lines indicate expression level of controls (normalized to 1), with \pm SEM indicated by the vertical arrows at right end of the control line. $\# p<0.05$ vs. control, ${ }^{*} p<0.05,{ }^{*} p<0.01$, ${ }^{* * *} p<0.001$.

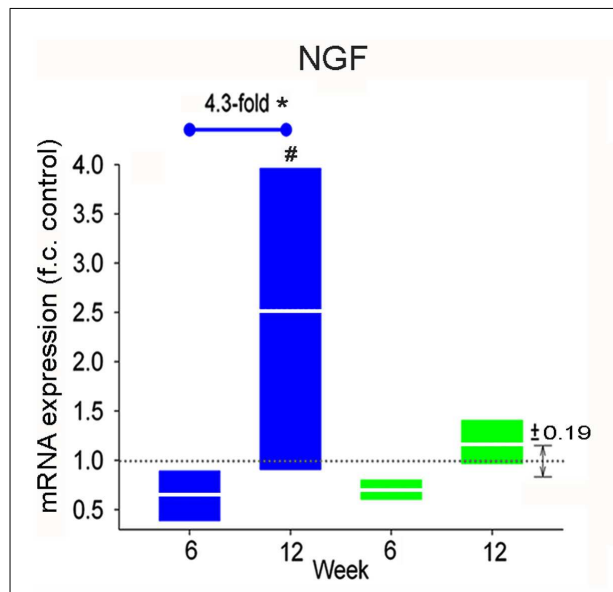

FIGURE 3 | mRNA expression of Neurotrophins is altered in L4/5 DRG at 6 and 12 weeks after receiving either $12.5 \mathrm{~g} \mathrm{~cm}$ (blue) or $25 \mathrm{~g} \mathrm{~cm}$ (green) NYU contusion injury to spinal cord at vertebral levelT9. Fold-change ( $f c$ ) is reported as change of 12 week relative to 6 week time points in all figures.
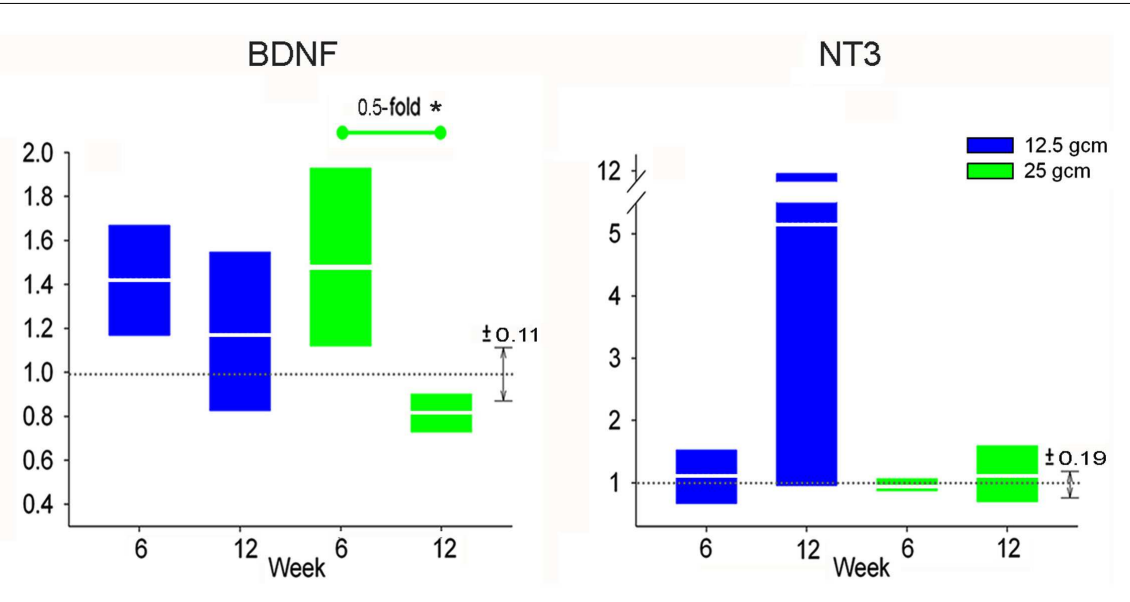

$X$ axis denotes weeks post injury. White lines in box-plots indicate group mean. Dotted gray lines indicate expression level of controls (normalized to 1), with \pm SEM indicated by the vertical arrows at right end of the control line. $\# p<0.05$ from control. ${ }^{*} p<0.05,{ }^{* *} p<0.01,{ }^{* *} p<0.001$. expression. For the neurotrophin genes in SC, however, expression differed significantly between the 6- and 12-week control groups (Figure 5A). We first analyzed these gene expression data exactly as was done for the other tissues - comparing each injury severity and survival time to the mean and variation of a single unified control group - but for the sake of clarity we have presented the data from the individual animals in each group. Caution must be exercised when considering the expression data for the experimental groups in this analysis (Figure 5A) because of the use of a unified control group - i.e., these data were generated exactly as were the other expression values, but are relative to a unified control group that, in this case, is not a suitable control group. We found decreases between our 6 and 12 week control groups in expression levels of NGF, BDNF, and NT3 in the SC in the absence of SCI. It is worth noting that our quality control measures were repeated for these samples, but the assessments remained the same. In ruling out technical issues and variability due to the necessity of using animals from different litters, a single factor appears to account for the altered expression levels in the control groups, that being age.

Because the gene expression differed between the 6- and 12week control groups, we cannot incorporate the temporal characteristic of the experimental design in our assessment of neurotrophin expression in SC. We are limited to analyzing the effect of injury severity on gene expression within each separate survival time group, where the data from experimental groups is expressed relative to the time-matched control group only (Figure 5B). Considered in this way, SCI itself did not significantly influence expression of any neurotrophin at any time considered, with the 

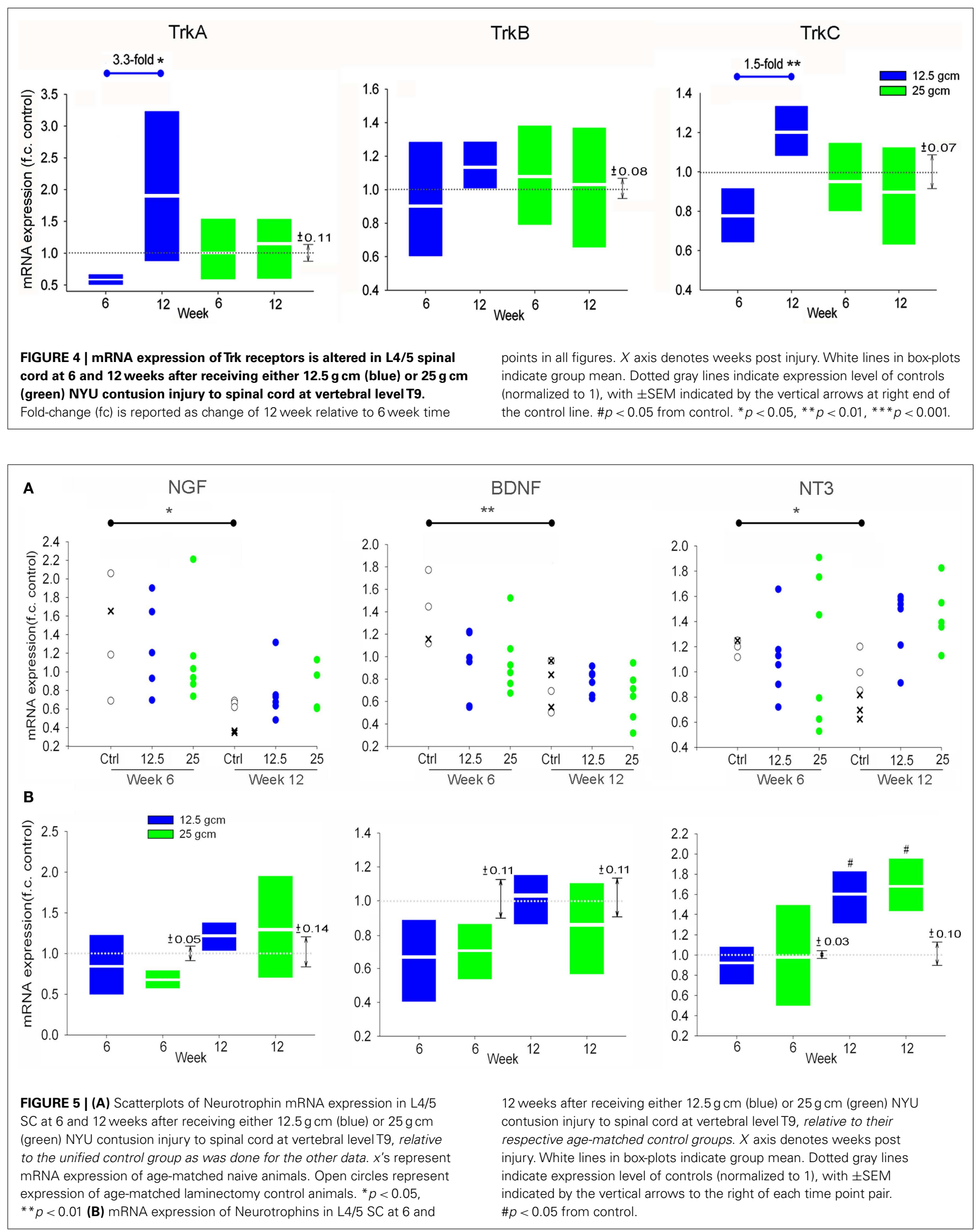
exception of NT3 at 12 weeks post-SCI. At this time, NT3 was elevated relative to the time-matched control group, with no effect of injury severity.

\section{RELATIONSHIP OF TRANSCRIPTIONAL ASSESSMENTS TO FUNCTIONAL} AND ANATOMICAL ASSESSMENTS

Our experimental design was intended to embrace the variability that exists with models of contusive SCI in that we also examined whether a statistical correlation existed between expression levels of each transcript and BBB or white matter sparing on an animal by animal basis. We observed no statistically significant correlation between the expression levels of the transcripts and BBB score or white matter sparing.

\section{COORDINATED EXPRESSION OF NEUROTROPHINS AND Trk RECEPTORS IN DRG AND SPINAL CORD 12 WEEKS POST INJURY}

To further characterize the relationship between the neurotrophins and their receptors in lumbar DRG and SC, we analyzed the expression levels of neurotrophins and Trk receptors relative to each other, and without respect for injury severity. In the SC, the only significant relationship was that of $\operatorname{TrkB}$ and $\operatorname{TrkC}$ in the control and 6 week groups. No relationship was found between any other expression levels at any time points in the SC (Table 3). In the DRG, there was a relationship between NGF and NT3 in all groups. In the 6-week groups the only other significant correlation observed was between BDNF and TrkB. After 12 weeks there was a significant correlation in the expression levels of all neurotrophins in the DRG, a relationship that existed for the Trk receptors as well (Table 4). Additionally, a significant correlation was observed between expression levels of neurotrophins and their cognate Trk receptors at 12 week time points (Table 4). This coordinated expression pattern occurred in all animals independent of injury severity (Figures 6 and 7). The reliability of this statistical assessment is enhanced by our performing the reverse-transcription for all samples with the same reagents, a procedure which reduces the cross-sample variability.

\section{BIOINFORMATIC ANALYSIS OF NEUROTROPHIN AND Trk RECEPTOR GENE REGULATION}

In light of the apparent coordinated expression of neurotrophins and trk receptors in DRG at 12 weeks after SCI, we used bioinformatic analyses to examine some possible mechanisms that may be at play. In order to assess possible coordination of regulation via gene promoters, we retrieved from the TransFac database (Wingender et al., 2000; Wingender, 2008; gene-regulation.com) all transcription factors (TFs) known/predicted to bind to (1) the annotated promoter region or (2) the sequence $1 \mathrm{~kb}$ upstream of the annotated translation start-site if the annotated promoter was less than $1 \mathrm{~kb}$, of all six genes examined here. For this procedure the RGSC 5.0/rn5 (March 2012; genome.ucsc.edu) rat genome assembly was used and all sequences and locations are relative to this assembly (Table 5). These broad results were filtered for those TFs with annotations indicating expression in nervous tissue, and results for different transcript entries for the same gene were pooled. TrkC was the only gene to lose all TFs in this filtering process, reflecting the fact that the assembled sequence upstream of the TrkC gene has numerous stretches of undefined bases, and that the annotated promoter is very short. In

Table 3 | Correlations between expression of mRNA for trk receptors in spinal cord.

\begin{tabular}{|c|c|c|c|c|c|c|}
\hline & \multicolumn{2}{|c|}{ Control } & \multicolumn{2}{|c|}{6 week } & \multicolumn{2}{|c|}{12 week } \\
\hline & $r$-Value & $p$-Value & $r$-Value & $p$-Value & $r$-Value & $p$-Value \\
\hline TrkA vs. TrkC & 0.42 & 0.26 & 0.21 & 0.53 & 0.4 & 0.19 \\
\hline TrkB vs. TrkC & 0.75 & 0.01 & 0.76 & 0.004 & 0.44 & 0.16 \\
\hline
\end{tabular}

Data in bold are statistically significant.

Table 4 | Correlations between expression of mRNA for neurotrophins, Trk receptors, and cognate pairs in DRG.

\begin{tabular}{|c|c|c|c|c|c|c|}
\hline & \multicolumn{2}{|c|}{ Control } & \multicolumn{2}{|c|}{6 week } & \multicolumn{2}{|c|}{12 week } \\
\hline & $r$-Value & $p$-Value & $r$-Value & $p$-Value & $r$-Value & $p$-Value \\
\hline NGF vs. BDNF & 0.20 & 0.61 & 0.15 & 0.69 & 0.84 & 0.001 \\
\hline NGF vs. NT3 & 0.72 & 0.03 & 0.87 & 0.003 & 0.92 & 0.00006 \\
\hline BDNF vs. NT3 & 0.10 & 0.80 & 0.33 & 0.38 & 0.88 & 0.0004 \\
\hline TrkA vs. TrkB & 0.04 & 0.90 & 0.005 & 0.989 & 0.89 & 0.0007 \\
\hline TrkA vs. TrkC & 0.56 & 0.11 & 0.61 & 0.08 & 0.79 & 0.006 \\
\hline TrkB vs. TrkC & 0.40 & 0.28 & 0.38 & 0.31 & 0.78 & 0.004 \\
\hline NGF vs. TrkA & 0.65 & 0.06 & 0.55 & 0.13 & 0.88 & 0.0004 \\
\hline BDNF vs. TrkB & 0.45 & 0.22 & 0.69 & 0.04 & 0.77 & 0.005 \\
\hline NT3 vs. TrkC & 0.57 & 0.11 & 0.61 & 0.08 & 0.77 & 0.006 \\
\hline
\end{tabular}

Data in bold are statistically significant. 

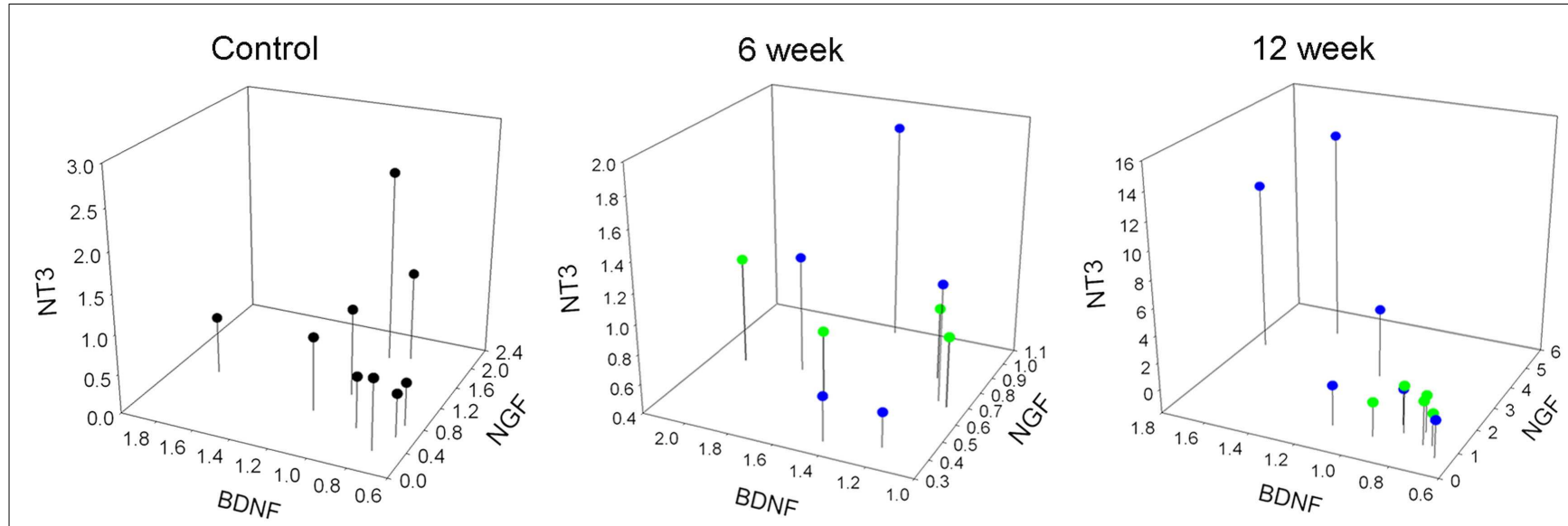

FIGURE 6 | Correlated expression of neurotrophins in DRG emerges at chronic time points. Values represent fold-change of the individual animals vs. mean of control group. Blue dots represent animals with $12.5 \mathrm{~g} \mathrm{~cm}$ injuries. Green dots represent animals with $25 \mathrm{~g} \mathrm{~cm}$ injuries.
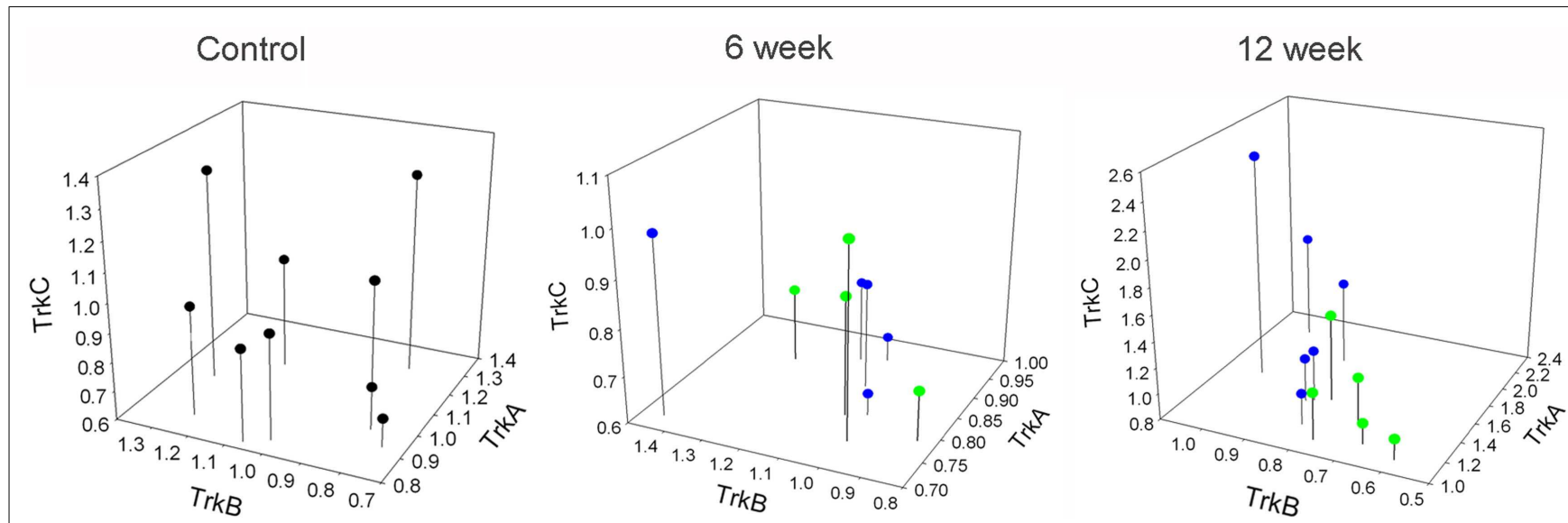

FIGURE 7 | Correlated expression of Trk receptors in DRG emerges at chronic time points. Values represent fold-change of the individual animals vs. mean of control group. Blue dots represent animals with $12.5 \mathrm{~g} \mathrm{~cm}$ injuries. Green dots represent animals with $25 \mathrm{~g} \mathrm{~cm}$ injuries.

spite of this, numerous TFs remained for three or more genes, and four TFs remained for all genes (except trkC) - cyclic AMP response element binding protein (CREB), MafB, NeuroD, and Pax3 (Table 6).

Another possible means of regulating the levels of mRNA is by micro-RNA (miRNA), which can influence the stability and/or turn-over rate of transcripts, among other effects (e.g., Kosik and Krichevsky, 2005). In order to assess possible coordination of regulation via miRNA, we retrieved from the TargetScan database those miRNA-binding sites that are conserved between human and rat neurotrophin and trk genes (TargetScanHuman release 6.2, e.g., Grimson et al., 2007; targetscan.org; Table 7). Although numerous miRNA species were retrieved, none were shared across any of the neurotrophin and trk genes.

\section{DISCUSSION}

\section{EXPRESSION AND FUNCTION OF NEUROTROPHINS AND Trks}

Spinal cord injury engenders a host of changes to both the central and peripheral nervous system, indeed for the entire organism, with residual functional capacity that is largely dependent on the location and severity of the injury. A variety of different approaches have been used in efforts to re-establish function, including enhancement of regeneration across the injury site (e.g., Bregman et al., 2002; Moon and Bunge, 2005; Sharma et al., 2012; Smith et al., 2012) and plasticity of intact circuits below the level of the lesion (e.g., Edgerton et al., 2004; Boulenguez and Vinay, 2009; Rossignol and Frigon, 2011). One means for achieving plasticity of intact circuits is through activity-dependent reorganization of inputs (e.g., Edgerton et al., 2004). This phenomenon has been described in studies of both animal (reviewed in Edgerton et al., 2008) and human (reviewed in Harkema, 2008) of SCI. Neurotrophins have been implicated as having a role in such changes (Hutchinson et al., 2004; Boyce et al., 2007, 2012; Côté et al., 2011). However, activity-dependent changes in the capacity for locomotion often manifest at times later than those examined in studies of post-SCI expression of neurotrophins and trk receptors (De Leon et al., 1998, 1999; Table 3). Indeed, the dynamic period of spontaneous locomotor recovery generally lasts for approximately 
Table 5 | Genomic coordinates used for Bioinformatic analyses.

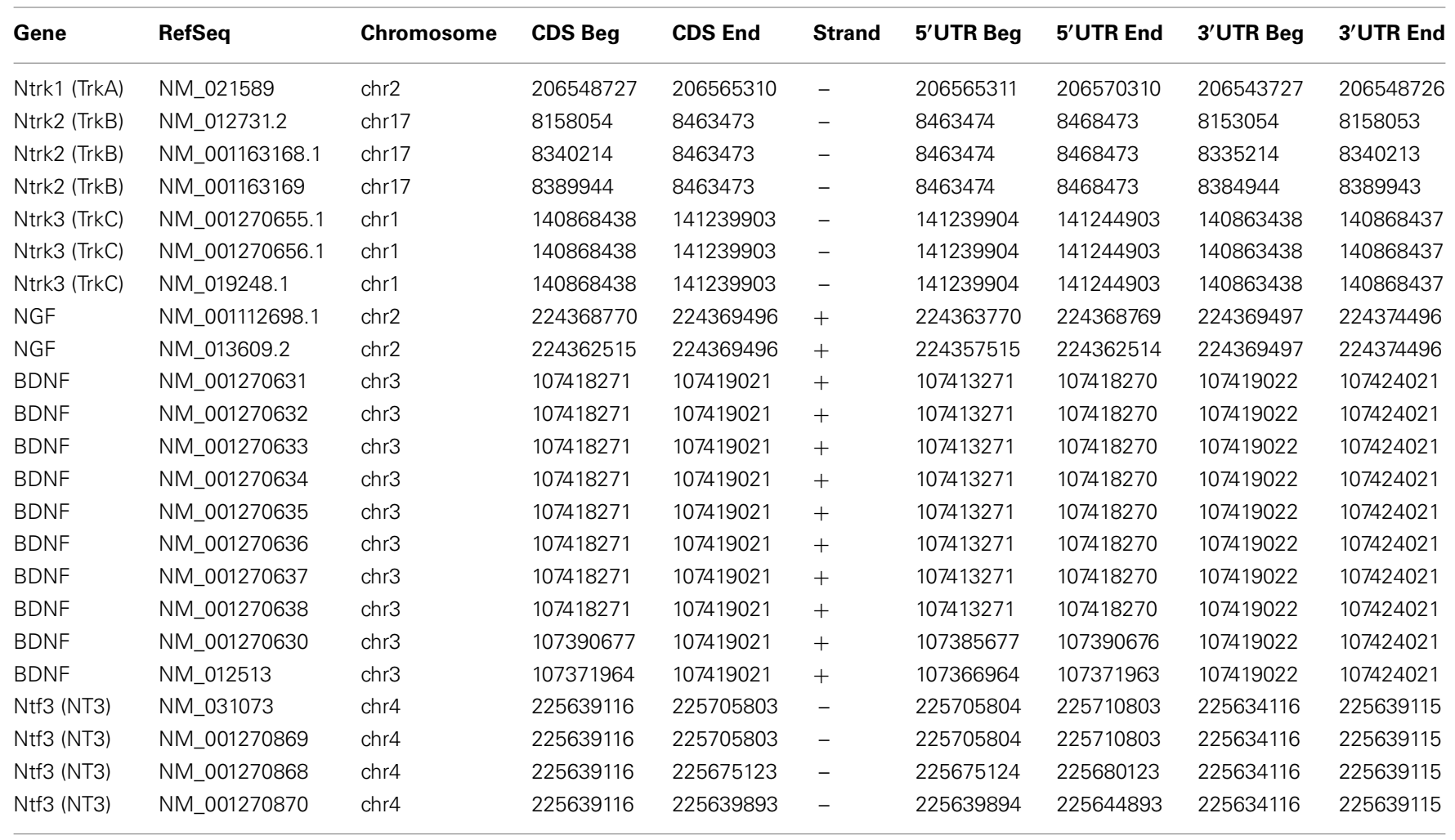

6 weeks after SCI, a time well beyond most prior studies (Table 3 ). In addition to a likely role in locomotor function, neurotrophin signaling is implicated in pathologic outcomes of plasticity such as post-SCI pain and autonomic dysreflexia (e.g., Brown and Weaver, 2012). The role of neurotrophin signaling has principally been examined in terms of initiation of these conditions in the near-term after SCI in animal models (Krenz et al., 1999; Marsh et al., 2002; Cameron et al., 2006), as opposed to later-phase initiation or maintenance. The regulation we have demonstrated at extended time points may provide new rationale for examining the role of neurotrophin signaling in later stages of these conditions.

Neurotrophins exert modulatory effects on cellular physiology through activation of their cognate Trk receptors (Lindsay, 1996; Patapoutian and Reichardt, 2001; Huang and Reichardt, 2003). In the DRG, expression of neurotrophin receptors is restricted to specific populations of cells. Generally, TrkA is expressed in neurons with small soma size, $\operatorname{TrkB}$ in neurons with intermediate size, and TrkC in neurons with large soma size; populations of TrkA and TrkC expressing neurons remain largely separate, whereas TrkB is co-expressed in overlapping populations of TrkA and TrkC positive cells (Mu et al., 1993; McMahon et al., 1994; Wright De, 1995; McMahon, 1996; Phillips and Armanini, 1996). Trk receptors are not ubiquitous, however, as there is a large subpopulation of small diameter DRG neurons which do not express any of the Trk receptors or the low-affinity neurotrophin receptor p75 in the adult (McMahon et al., 1994; Molliver and Snider, 1997; Bennett et al., 1998). In the mammalian SC, TrkA is expressed in second order nociceptors of the dorsal horn, TrkB has a broad pattern of expression which overlaps with both TrkA and TrkC expression, and TrkC is expressed in neurons of the intermediate and ventral horn (e.g., Duberley et al., 1997; Curtis et al., 1998; Schober et al., 1999; Copray and Kernell, 2000; Liebl et al., 2001; Allen Institute for Brain Science, 2009).

As long as 6 weeks after SC transection injury, the number of cells expressing TrkA and TrkB protein in L1 and L6/S1 DRG (containing bladder afferents) increases over controls, though the numbers of cells expressing these genes does not significantly change in L4/5 DRG (Qiao and Vizzard, 2002, 2005). Our analysis of Trk expression, which was also performed in L4/5 DRG and included a 6 -week post-SCI time point, found no significant change in the trkA or trkB mRNA levels for either severity of contusion injury, in agreement with the prior work. In intact sensory and sympathetic ganglia of the adult rat, NGF and NT3 (as well as $\operatorname{TrkA}$, full length $\operatorname{TrkB}$, and $\operatorname{TrkC}$ ), localize exclusively to neurons; $\mathrm{BDNF}$ and the truncated isoform of TrkB are expressed more extensively, however, localizing to neuronal cells and some glial and satellite cells (Wetmore and Olson, 1995). These observations are consistent with the notion that full length Trk expression predominantly occurs in neurons, though since the latter study was performed with intact animals, we cannot exclude the possibility that our injuries potentially resulted in expression in other cell types. Indeed, there are numerous reports of trk receptor expression by non-neuronal cells. In particular Schwann cells can express trks, as can cancer cells (e.g., Funakoshi et al., 1993; Tacconelli et al., 2005; Hess et al., 2007; Jin et al., 2011). Further, neurotrophins are 
Table 6 | Transcription factor binding sites for neurotrophin and trk receptor genes.

\begin{tabular}{|c|c|c|c|c|c|c|c|}
\hline TF Binding-site name & HGNC symbol & TrkA & NGF & TrkB & BDNF & TrkC & NTF3 \\
\hline AhR & AHR & $x$ & & $x$ & $x$ & & \\
\hline AhR: Arnt & & & & & $x$ & & \\
\hline AP-1 & FOS; FOSB; JUN; JUND & & $x$ & & $x$ & & \\
\hline AP-2 & TFAP2A & $x$ & $x$ & $x$ & $x$ & & \\
\hline$A R$ & AR & & & $x$ & $x$ & & \\
\hline Arnt & ARNT & & & $x$ & & & \\
\hline ATF & ATF & $x$ & & $x$ & & & \\
\hline ATF2 & ATF2 & $x$ & $x$ & $x$ & $x$ & & \\
\hline ATF2: C-Jun & & & $x$ & & & & \\
\hline Brn-2 & POU3F2 & & & & $x$ & & \\
\hline C/EBP & CEBPA, B, D, E, G, Z & $x$ & & & $x$ & & \\
\hline CAR & NR1।3 & $x$ & & & & & \\
\hline c-Ets-2 & ETS2 & & $x$ & & & & \\
\hline C-Jun & JUN & $x$ & & $x$ & & & \\
\hline c-Myc: Max & & $x$ & & & & & \\
\hline COUP-TF1 & $\mathrm{NR} 2 \mathrm{~F} 1$ & & $x$ & & $x$ & & $x$ \\
\hline CREB & CREB1 & $x$ & $x$ & $x$ & $x$ & & $x$ \\
\hline CREB, ATF & & & & & $x$ & & \\
\hline CREM & CREM & $x$ & & $x$ & & & \\
\hline DEC & BHLHE40 & $x$ & $x$ & & $x$ & & \\
\hline E2A & TCF3 & & & $x$ & & & \\
\hline Ebox & TCF3; MYOD1; MYOG & & & $x$ & & & \\
\hline ER-alpha & ESR1 & & & & $x$ & & $x$ \\
\hline Ets & ETS1, 2; ETV1, 2, 3, 4, 5, 6, 7 & & $x$ & & $x$ & & $x$ \\
\hline Foxj1 & FOXJ1 & & & & & & $x$ \\
\hline FOXO1 & FOXO1 & & & & & & $x$ \\
\hline GATA-3 & GATA-3 & & & & $x$ & & $x$ \\
\hline GR & NR3C1 & & $x$ & $x$ & $x$ & & \\
\hline HES1 & HES1 & & & $x$ & & & $x$ \\
\hline HOXA5 & HOXA5 & & $x$ & & & & \\
\hline HOXB8 & HOXB8 & $x$ & & & & & \\
\hline KROX & EGR1，2; ZNF22; ZBTB7B & & & & $x$ & & \\
\hline MAF & MAF & & $x$ & $x$ & $x$ & & $x$ \\
\hline MAFB & MAFB & $x$ & $x$ & $x$ & $x$ & & $x$ \\
\hline Max & MAX & $x$ & & & $x$ & & $x$ \\
\hline MEF-2 & MEF-2A & & & & & & $x$ \\
\hline MEF-2C & MEF-2C & & & & $x$ & & \\
\hline Myc & MYC & $x$ & & & $x$ & & \\
\hline Neuro D & NEUROD1 & $x$ & $x$ & $x$ & $x$ & & $x$ \\
\hline NFAT1 & NFATC2 & $x$ & $x$ & & $x$ & & $x$ \\
\hline NF-AT4 & NFATC3 & $x$ & $x$ & & $x$ & & $x$ \\
\hline NF-kappaB & NFKB1 & & $x$ & & & & \\
\hline NKX2B & NKX2-2 & & $x$ & & & & \\
\hline NRSF & REST & & $x$ & & & & \\
\hline NURR1 & NR4A2 & $x$ & $x$ & & $x$ & & \\
\hline Oct-1 & POU2F1 & & $x$ & & $x$ & & \\
\hline Octamer & POU family of proteins & & $x$ & & $x$ & & \\
\hline Oct-x & STAT1 & & $x$ & & & & \\
\hline p53 & TP53 & & & & & & $x$ \\
\hline Pax3 & PAX3 & $x$ & $x$ & $x$ & $x$ & & $x$ \\
\hline Pax6 & PAX6 & & & & & & $x$ \\
\hline
\end{tabular}


Table 6 | Continued

\begin{tabular}{|c|c|c|c|c|c|c|c|}
\hline TF Binding-site name & HGNC symbol & TrkA & NGF & TrkB & BDNF & TrkC & NTF3 \\
\hline Pax8 & PAX8 & & $x$ & $x$ & $x$ & & \\
\hline $\mathrm{Pbx} 1$ & PBX1 & & $x$ & & $x$ & & $x$ \\
\hline POU6F1 & POU2F1 & & & & $x$ & & \\
\hline POUF2F1 & POU6F1 & & $x$ & & & & \\
\hline PPARgamma & PPARG & & & $x$ & & & \\
\hline PPARgamma: RXR-alpha & & & & $x$ & & & \\
\hline PXR & NR1I2 & $x$ & & & & & \\
\hline RXR-alpha & $\mathrm{RXRA}$ & & & $x$ & $x$ & & \\
\hline SF1 & SF1 & & & & & & $x$ \\
\hline SMAD & MADH family of proteins & & & & $x$ & & $x$ \\
\hline Smad3 & SMAD3 & & & & $x$ & & $x$ \\
\hline Sox1 & SOX1 & & & & $x$ & & $x$ \\
\hline Sox2 & sox2 & & $x$ & & & & \\
\hline Sp1 & SP1 & $x$ & $x$ & & $x$ & & $x$ \\
\hline SRF & SRF & & $x$ & & & & \\
\hline Sry & SRY & & $x$ & & $x$ & & $x$ \\
\hline STAT & SOAT1 & & $x$ & & $x$ & & $x$ \\
\hline STAT1 & STAT1 & & $x$ & & & & \\
\hline STAT3 & STAT3 & & $x$ & & $x$ & & \\
\hline Tax & CNTN2 & & & $x$ & & & \\
\hline Tax/CREB & & & & & $x$ & & $x$ \\
\hline Tbp & TBP & & & $x$ & $x$ & & $x$ \\
\hline TCF4 & TCF4 & $x$ & & & & & \\
\hline Tcfap2a & TFAP2A & & & & $x$ & & \\
\hline Tcfap2b & TFAP2B & & & & $x$ & & \\
\hline Tst-1 & CCDC6 & & $x$ & & & & \\
\hline USF & USF1 & & & & $x$ & & \\
\hline USF2 & USF2 & & & & $x$ & & \\
\hline VDR & VDR & $x$ & & & & & \\
\hline VDR, CAR, PXR & & & & & $x$ & & $x$ \\
\hline
\end{tabular}

Entries with transcription factors separated with a ": " have binding sites situated such that they act in a cooperative fashion, rather than independent from each other. Entries with transcription factors separated by a "'share binding sites or have binding sites situated near each other such that the factors act in competition with each other.

often expressed in non-neuronal cells, most notably by cells outside the nervous system where they influence both developmental and adult processes (e.g., Lewin, 1996; Petruska and Mendell, 2004).

Previous assessments of changes in neurotrophin/Trk receptor expression levels after SCI have typically focused at time points of less than 6 weeks. BDNF expression increases up to 2 weeks after injury in the SC after thoracic transection and crush injury (Hayashi et al., 2000; Li et al., 2007), though both increases and decreases in expression have been reported after hemisection during a similar time period post injury (Gulino et al., 2004; Qin et al., 2006). Expression levels of NGF and NT3 in the cord increase for up to 3 weeks after SCI (Hayashi et al., 2000; Li et al., 2007). In another study, NGF and BDNF transcripts were found to increase up to 4 days following injury in the adult cord, however, by 2 weeks post injury all neurotrophins were expressed at levels similar to that of control (Nakamura and Bregman, 2001; Widenfalk et al., 2001), suggesting expression decreases after an early increase, though these studies used different injury models. Trk mRNA expression is downregulated acutely in the SC at and around the injury site after contusion (Liebl et al., 2001; Hajebrahimi et al., 2008), however by 6 weeks expression levels are not different from control (Liebl et al., 2001). However, after SC transection TrkC has been shown to increase after 2 weeks (Qian et al., 2011). Similarly, in a recent study assessing mRNA and protein changes after transection at 10 and 31 days post injury, whole SC TrkB mRNA was elevated at 10 days post injury, and whole SC NT3 and TrkB protein was elevated at 31 days post injury, with expression differences also observed depending on the location within the parenchyma of the SC (Keeler et al., 2012). Table 1 summarizes the findings of recent experiments to facilitate comparison of these results.

We found TrkA expression increases in both the DRG and SC of animals after contusion in a manner that was dependent on injury severity. This finding is of particular interest with regards to the functions of NGF and TrkA. NGF plays a well-defined role in sensitization of nociceptive afferent neurons (e.g., Shu 
Table 7 | Micro-RNA binding sites for neurotrophin and trk receptor genes.

\begin{tabular}{ll}
\hline Gene symbol & miRNA symbol \\
\hline Ntrk1 (TrkA) & n/a \\
Ntrk2 (TrkB) & rno-miR-325p \\
Ntrk2 (TrkB) & rno-mir-211 \\
Ntrk2 (TrkB) & rno-miR-204 \\
Ntrk3 (TrkC) & rno-mir-128 \\
Ntrk3 (TrkC) & rno-miR-466b \\
Ntrk3 (TrkC) & rno-miR-297 \\
Ntrk3 (TrkC) & rno-miR-3592 \\
NGF & rno-let-7e \\
NGF & rno-let-7d \\
NGF & rno-let-7b \\
NGF & rno-let-7c \\
NGF & rno-let-7a \\
NGF & rno-miR-98 \\
NGF & rno-let-7f \\
NGF & rno-let-7i \\
BDNF & rno-miR-10a-5p \\
Ntf3 (NT3) & rno-miR-222 \\
Ntf3 (NT3) & rno-miR-221 \\
&
\end{tabular}

and Mendell, 1999, 2001; Galoyan et al., 2003; Zhu et al., 2004b). Nociceptive DRG neurons undergo changes after SCI, including development of spontaneous activity (Bedi et al., 2010) and an enhanced intrinsic growth promoting state (Bedi et al., 2012). Such changes in anatomical and physiological properties of nociceptors may contribute to development of conditions such as autonomic dysreflexia (e.g., Marsh et al., 2002). TrkA antagonists prevent the sensitization (thermal and mechanical hyperalgesia) normally induced by partial nerve injury (Ma et al., 2010), and antagonism of TrkA signaling has been effective for controlling human pain (Mantyh et al., 2011). Hence, elevation in the levels of TrkA and NGF in response to contusive injury could play a role in some of the maladaptive processes after incomplete SCI.

TrkB activation has also been implicated in hypersensitivity to nociceptive input and sensitization of nociceptors (Kerr et al., 1999; Shu et al., 1999; Garraway et al., 2003). However, after either SC transection or contusion injury, BDNF induced facilitation of afferent responses in lamina II of the dorsal horn is significantly reduced (Garraway et al., 2005; Garraway and Mendell, 2007). Our results could suggest a mechanism for those physiological observations. In addition to TrkB expression in populations of second order nociceptive neurons (Schober et al., 1999), it is expressed robustly throughout the interneuronal circuitry, and also co-expressed along with NT3 in motoneurons (Buck et al., 2000), a finding corroborated in humans (Josephson et al., 2001). Notably, BDNF administration to the injured SC can improve locomotor outcomes, however because of its influence on nociceptive circuitry its therapeutic utility may be limited (Boyce et al., 2012).

In DRG, TrkC is present on medium to large diameter muscle spindle afferents that make monosynaptic connections with motoneurons and cutaneous low threshold mechanoreceptors
(Klein et al., 1994; Oakley et al., 1997; Josephson et al., 2001) in the intermediate and ventral horns of the SC. NT3, likely acting via TrkC, exerts a modulatory effect on sensorimotor circuits in both intact (Petruska et al., 2010) and injured preparations (Mendell et al., 2001; Arvanian et al., 2003; Arvanian et al., 2006a,b; GarcíaAlías et al., 2011; Schnell et al., 2011). Locomotor training after $\mathrm{SCI}$ is associated with increased expression levels of TrkB and TrkC agonists in rats (Hutchinson et al., 2004; Côté et al., 2011). In addition, co-administration of both BDNF and NT3 to the injury site has been shown to improve hindlimb locomotion after transection in both rats (Blits et al., 2003) and cats (Boyce et al., 2007). Taken together, these findings suggest a potential role for Trk activation in modulation of lumbar sensorimotor circuitry in both intact and injured animals.

The apparent age-related regulation of NGF, BDNF, and NT3 in non-injured SC was unexpected and we made significant efforts to identify possible technical and sampling issues. While those factors that often account for variability did not satisfactorily account for the expression patterns we observed, the single factor of age did appear to fully account for the differences. Expression of the neurotrophins has been examined in the context of embryonic and postnatal development and in aging (e.g., Timmusk et al., 1994; Nosrat, 1998; Bergman et al., 2000). However, to the best of our knowledge, there has been no systematic assessment of the regulation of the neurotrophins at such late postnatal times. If it is indeed borne out that neurotrophins are regulated in the SC over a long postnatal time course, this must be taken into account when designing experiments that may be influenced by the natural progression of this expression.

\section{COORDINATED EXPRESSION OF NEUROTROPHINS AND Trks}

Twelve-weeks after injury a coordinated expression pattern existed among the levels of all neurotrophins and Trk receptors regardless of injury severity, and also between the neurotrophins and their cognate Trk receptors in the DRG (Tables 1 and 2, Figures 5 and 6), a relationship that was not evident at 6 weeks post-SCI. Although there are reports of smaller groups of neurotrophins and/or Trks being regulated in a coordinated fashion (e.g., Widenfalk et al., 1999), to our knowledge this degree of coordination has not been reported, and the mechanism is unclear. One obvious possibility is a feedback/feed-forward relationship between some/all of these genes, and these sorts of relationship do exist (e.g., Michael et al., 1997; Wyatt et al., 1999; Gibbons and Bailey, 2005).

Neurotrophin dependent neurotrophin expression has been demonstrated in vitro in NIH3T3 and PC12 cells (Canossa et al., 1997; Mallei et al., 2004), hippocampal neurons (Canossa et al., 1997), and cerebellar granule neurons (Leingärtner et al., 1994). In vivo, intrathecal administration of NT3 to intact adult animals for 1 week results in reduced expression of TrkA protein in the DRG, but has no effect on levels of TrkC (Gratto and Verge, 2003). After unilateral axotomy, sub-cutaneous administration of exogenous NT3 similarly causes a decrease in TrkA on the side contralateral to the injury. This contrasts to the increase in TrkA expression seen on the side ipsilateral to the injury; the effect of NT3 on expression levels of TrkB and TrkC however is 
not affected by injury in this paradigm, as levels of these transcripts show increased expression up to 4 weeks post axotomy in both ipsi- and contra-lateral DRG (Kuo et al., 2007). Such coordinated expression patterns could potentially result from changes at the epigenetic level or from interactions between the different transcription factors associated with expression of specific transcripts. During development, Runx1 and Runx3 transcription factors play essential roles in cell fate determination of nociceptive (Chen et al., 2006) and proprioceptive (Inoue et al., 2002) neurons, respectively. Much attention regarding transcriptional regulation of neurotrophin expression in the mature nervous system has been given to BDNF, due to its role in activity-dependent mechanisms during long-term potentiation (LTP). Such investigations have revealed several important transcriptional regulators including, CREB, calcium-responsive transcription factor (CaRF), and methyl CpG-binding protein 2 (MeCP2; Tao et al., 1998, 2002; Chen et al., 2003; Reichardt, 2006). Such findings may facilitate future efforts to determine the mechanisms regulating the expression of the neurotrophins and Trk receptors in the injured adult SC and sensory ganglia.

The lack of any TFs for trkC after the filtering process is more a reflection of the relative amount of data available than reality. The filtering step in the bioinformatic analysis involved the use of annotations, which, valuable though they are, have inherent limitations. Certainly there are published data regarding factors involved in regulating the expression of trkC, particularly Runx3 (Levanon et al., 2002), Brn3a/Pou4f1 and Runx1 (Zou et al., 2012), and REST/NRSF (Nakatani et al., 2005).

In spite of the lack of any result related to TrkC, four TFs did emerge as possibly interacting with all of the remaining genes. The majority of published information related to these genes and their involvement in regulation of neurotrophins and Trks is in the context of development or cancer. This does not imply that they function exclusively in those contexts, but only that those contexts are the most studied. We could not identify any studies examining Pax3, NeuroD, or MafB in SC or DRG in the context of SCI. Maf has been studied in relation to neurodegeneration (Kobayashi et al., 2011) and in stress (Machiya et al., 2007). Pax3 was studied in relation to nerve injury, where it was found to not be regulated (though this does not imply it not being active; Vogelaar et al., 2004).

There are studies examining CREB in SC (Crown et al., 2005, 2006; Yu and Yezierski, 2005; Yune et al., 2008) or DRG (Qiao and Vizzard, 2005) in the context of SCI, with the latter study examining TrkA, TrkB, and CREB, though not in direct relation to each other. Interestingly, the expression of activated CREB in the DRG changed over the course of the first 6 weeks after SCI, with the levels at 6 weeks being significantly greater than controls, though not in the DRG we examined here. Other studies demonstrate induction of CREB in injured/stressed neurons and also in neurons post-synaptic to stressed sensory neurons (e.g., Ji and Rupp, 1997; Bedogni et al., 2003; Choi et al., 2003; He et al., 2003; Zhu et al., 2004a), while others demonstrate CREB regulating multiple NTs (Bender et al., 2001), in at least one case by interacting with cytokines (Otten et al., 2000).

Unlike the results of the analysis of the gene promoter regions using the TransFac database, the set of miRNAs that emerged from the TargetScan analysis of gene 3'-UTRs were not shared across multiple genes. It should be noted that these analyses necessarily have certain differences that certainly impacted the results. Most notable is that TargetScan returns only those miRNA targets that have experimental confirmation. The data in Table 7 could therefore be considered a snapshot of the current experimental data regarding which miRNA species interact with those genes (Saba et al., 2008; Guidi et al., 2010; Natera-Naranjo et al., 2010; Rau et al., 2010; Smith et al., 2010; Benoit and Tenner, 2011; Farrell et al., 2011; Kawahara et al., 2011, 2012; Yu et al., 2011, 2012; Brandenburger et al., 2012; Hamada et al., 2012; Ryan et al., 2012; Wang et al., 2012). Thus, although our analysis revealed no common miRNA species that interacted with multiple genes (representing a possible common regulatory mechanism), this may yet be the case.

Because our data are derived from homogenized tissue, we cannot make any conclusions about the cellular basis of this apparent coordinated expression. That is, we cannot determine which aspect, if any, of this coordination is occurring within single cells, or if it is simply occurring within the same tissue but arises through expression of different combinations of genes across different cells. Considerations of this issue here are at best speculative as there are virtually no studies that can provide information directly relevant to the question. Relevant information would include (1) an indication of which types of cells were expressing the genes, or at least if they were neural, non-neural, or both, (2) an indication of whether or not any combination of the genes were expressed in any single cells, and both of these would (3) have to be sampled from DRG or SC 12 weeks after SCI. We are not aware of any studies fitting these criteria (Table 1). Although the relationship is not direct, we can nonetheless draw from a number of sources to make inferences about what may be happening.

(1) There is some evidence that at 6 weeks after SCI Trk receptors are expressed almost exclusively in DRG neurons, much as before the SCI (Qiao and Vizzard, 2002, 2005). However, it must be noted that there is a plethora of evidence of expression of NTs and Trks in non-neuronal cells (e.g., Funakoshi et al., 1993; Elkabes et al., 1998; Nemoto et al., 1998; Noga et al., 2002; Hess et al., 2007), although much of this is in the context of cancer (e.g., Tacconelli et al., 2005; Howe et al., 2011; Jin et al., 2011). Studies which identify the cell types expressing the NTs or Trks are necessary as it is possible that at least a portion of the tissue-level regulation could be due to invading cells. Certainly the complement of immune cells in the SC is affected by injury, even in segments spatially remote from the injury (e.g., Popovich et al., 1997). Immune cells invade the DRG after nerve injury (e.g., Nguyen et al., 2007; Vega-Avelaira et al., 2009; Kim and MoalemTaylor, 2011), but there is no indication that this possibility has been examined in DRG at any time after SCI. However, evidence suggests that the immune cells and their functions throughout the body may be affected by SCI (e.g., Popovich et al., 2001), and some express Trk receptors and/or neurotrophins (e.g., Noga et al., 2002; Nassenstein et al., 2004; Tabakman et al., 2004). 
(2) There is evidence that single neurons can express certain limited combinations of the genes examined here, though to our knowledge there has been no examination of all together that could distinguish each of the Trk receptors and neurotrophins (e.g., McMahon et al., 1994; Obata et al., 2004).

(3) There are certainly studies which examine the chronic postSCI condition, but we could not identify any that could provide data relevant to these specific considerations (i.e., they examined other readouts).

Almost irrespective of the outcome of the above considerations, there is still another consideration that can be brought to bear. Although there are a number of papers describing coexpression of some of these genes in single cells where common genetic/molecular regulation could possibly be exerted, it is highly unlikely that all the coordinated expression is accounted for by single cells. Even in the feasible condition where expression is limited to neurons, and perhaps even to the same population of neurons that expressed these genes in the intact system (i.e., differences in expression would be based on volume regulation in any given cell and not on recruitment/de-recruitment of cell populations), what is the likelihood that this degree and scope of coordinated expression could occur across different cell types independently? It seems highly unlikely that each of the genes considered here would change in a single cell type independent of its regulation in any other cell type, and still give rise to this result. However, because there is little-to-no cellular expression data here or in the literature from which to extrapolate the identity of the cells expressing these genes (i.e., immunocytochemical or in situ hybridization assessment of SC or DRG 12 weeks post$\mathrm{SCI}$ ), we must acknowledge that this is indeed possible in principle. There is, however, virtually no reason to expect that individual cells would express all of the "coordinated" genes and thus have the mechanism of coordinated regulation exist fully inside of those given single cells. Therefore, at least some of the coordination must arise across cells which express one or more of the "coordinated" genes.

It is possible that coordinated regulation/expression may arise due to shared direct molecular mechanisms, but the literature and our bioinformatic analyses provide little evidence for a simple mechanism of this sort. There may yet be coordinated transcriptional regulation that is indeed shared across cell types, but may reside at a level above our analyses (i.e., shared factors may be directing the actions of separate factors that then individually act on the different genes). Alternatively, there may be a shared biological process(es) or response(es) that is being executed in the various different cells - a process that has similar outcomes in terms of gene regulation but arrives there through the actions of different specific molecular entities. For "simplicity," let us consider that only the neurons of the DRG are involved. Even this cell population is not homogeneous in function, form, or sensitivity. Each of the Trk receptors is largely separately expressed. Given the dissimilarities of their regulatory sequences, they may each be directly regulated by distinct factors. However, conditions may arise that induce the non-homogeneous neuronal types, regardless of the specific Trk they express (and thus which specific factors will act on the DNA and/or mRNA), to coordinately regulate the expression of their
Trk receptor. It is possible that the regulation of those specific factors may be under a control mechanism that is itself shared across the different neuron types. Our analysis would not detect this. As an example, consider cellular stress or injury. Numerous authors have reported on the regulation of Trks and neurotrophins in response to nerve injury, and the change in expression over time (e.g., Ernfors et al., 1993; Sebert and Shooter, 1993; Krekoski et al., 1996; Yamamoto et al., 1996; Bergman et al., 1999; Lee et al., 2001; Kuo et al., 2007), and many aspects of our data coincide with the reported regulation after nerve injury or neuronal stress. Intriguingly, there was another report of "coordinated regulation" associated with DRG neurons and glia in conditions of injury and/or stress (Cameron et al., 2003).

It is not clear if SCI induces any long-term injury or stress on DRG neurons. Certainly the central axons of some DRG neurons are damaged in the SCI, particularly those terminating in the affected cord, or with long axons ascending through the dorsal columns (Huang et al., 2006). However, the effect of injury to central axons differs from that of injury to peripheral axons (e.g., Stam et al., 2007), and the long-term effects on expression of neurotrophins and Trk receptors has not been examined. Injury to central axons is not the only possible source of stress to the sensory neurons, however. The inflammatory condition of the SC and continued spread of damage may induce injury or stress in the sensory neurons at times remote from the acute SCI, and at locations remote from the lesion (e.g., Popovich et al., 1997; Popovich, 2000; Bao et al., 2004, 2011; Fleming et al., 2006; Gris et al., 2008; Kwon et al., 2010; Lubieniecka et al., 2011; Ng et al., 2011; Stammers et al., 2012). There is a systemic inflammatory condition (Fleming et al., 2006; Gris et al., 2008; Bao et al., 2012) that has unknown effects on these neurons. Additionally, one must consider the effects of SCI on the peripheral tissues innervated by the sensory and motor neurons. The inflammation and altered activity/mobility/use state can impact these tissues (e.g., Edwards-Beckett and King, 1996; Lynch et al., 2000; Gris et al., 2008) with uncertain consequences for the innervating neurons. The increased expression of galanin, a neuropeptide induced in DRG neurons by stress/injury (Suarez et al., 2006), in the DRG innervating bladder and bowel (but not other DRG) after SCI (Zvarova et al., 2004) suggests that the histopathology secondary to SCI may stress the sensory neurons innervating those tissues. Tissue damage has been shown to induce stress/injury responses in sensory neurons (e.g., Ivanavicius et al., 2007; Hill et al., 2010; Thakur et al., 2012), and has been shown to affect regulation of multiple neurotrophins in the injured tissue (Vizzard, 2000).

\section{REGULATION OF NEUROTROPHINS AND Trks AFTER SCI: ENOUGH ASSESSMENT OR NOT?}

Although there are many reports examining the expression of neurotrophins and/or Trk receptors after SCI, there is relatively little overlap of the data (Table 1), and general principles have yet to be identified. That is not to say that the data disagree, but more that the studies have largely produced different data. Indeed, given the number of factors that influence gene regulation after SCI, much work is yet to be done. A matrix of variables demonstrated by our study and others to significantly impact the regulation of these genes suggests that over 1000 assessments would be 
Table 8 | Matrix of factors influencing outcomes in SCl research.

\begin{tabular}{llll}
\hline Injury type/severity & Injury location & $\begin{array}{l}\text { Region } \\
\text { investigated }\end{array}$ & $\begin{array}{l}\text { Post-SCI } \\
\text { time }\end{array}$ \\
\hline Hemisection - lateral & Cervical & Cervical & 1-3 days \\
Hemisection - DN & Brachial plexus & Brachial plexus & 3-7 days \\
Transection & Thoracic & Thoracic & $1-3$ weeks \\
Contusion - mild & Lumbar & Lumbar & 3-6 weeks \\
Contusion - moderate & Lumbar plexus & Lumbar plexus & 6-12 weeks \\
Contusion - severe & Sacral & Sacral & $12-24$ weeks
\end{tabular}

required to provide relatively thorough coverage (Table 8). This matrix relates only to natural progression and does not include variables for the two sexes, different species and strains, and outcome measures (e.g., protein, mRNA, behavior, etc.). It would thus only be expanded when considering treatments, sex/species/ strain-differences, and multiple outcome measures (some of which are mutually exclusive), each of which has been shown to influence the data (e.g., Popovich et al., 1997; Sroga et al., 2003; Kigerl et al., 2006; Beck et al., 2010).

This study examined only mRNA expression levels, which could change due to a limited set of non-mutually exclusive scenarios. Cells already expressing the specific transcripts could up- or downregulate expression, or a different population of cells - resident or infiltrating - could begin expressing these transcripts de novo. Our data cannot speak to the relative contribution of these possibilities as they come from homogenized tissue. Although the literature provides some insight for the 6-week post-SCI data, this is not true for the 12-week data as neurotrophins and Trk receptors have not been examined at 12 weeks post-SCI (Table 1). Further, we are

\section{REFERENCES}

Ackery, A. D., Norenberg, M. D., and Krassioukov, A. (2007). Calcitonin gene-related peptide immunoreactivity in chronic human spinal cord injury. Spinal Cord 45, 678-686.

Agrawal, G., Kerr, C., Thakor, N. V., and All, A. H. (2010). Characterization of graded multicenter animal spinal cord injury study contusion spinal cord injury using somatosensory-evoked potentials. Spine 35, 1122-1127.

Allen Institute for Brain Science. (2009). Allen Spinal Cord Atlas [Internet]. Seattle, WA. Available at: http://mousespinal.brain-map.org

Arvanian, B. W. VI, Anderson, A., Horner, P. J., Federoff, H. J., Mendell, L. M. (2006a). Combined delivery of neurotrophin-3 and NMDA receptors $2 \mathrm{D}$ subunit strengthens synaptic transmission in contused and staggered double hemisected spinal cord of neonatal rat. Exp. Neurol. 197, 347-352.

Arvanian, M. H. VI, Davenport, M., Bushell, G., Mendell, L. M., and ery from double-hemisection spinal

Bao, F., Chen, Y., Dekaban, G. A., inflammatory response after spinal

not aware of any work examining whether cells infiltrate the DRG after SCI.

\section{CONCLUSION}

Despite the limitations of examining only mRNA expression, this study has established that different injury severities within the same model can result in different forms of regulation of these important genes in neural tissue. It has also demonstrated that expression of these genes in neural structures providing innervation to the hindlimb changes over a time course important for experiments examining activity-dependent plasticity and also for modeling the human condition. Thus, this study (1) offers insight for interpreting published data and for designing future studies; (2) serves as a reference for mechanistic studies that manipulate the neurotrophin-Trk signaling systems, (3) indicates that injury severity, post injury time, and tissue sampled all influence the assessments of gene regulation, (4) suggests that regulation of these genes continues to occur as late as 12 weeks post-SCI, and (5) suggests that some common factor or process may be influencing expression of these genes at later times after SCI.

\section{ACKNOWLEDGMENTS}

The authors thank the staff of the Kentucky Spinal Cord Injury Research Center Core facilities [supported by NIH P30-RR031159 and the Kentucky Spinal Cord and Head Injury Research Trust (KSCHIRT)] for excellent technical assistance, and John Gensel for assistance with some of the literature. Financial support for this project was provided by KSCHIRT (\#09-12A to Jeffrey C. Petruska and David S. K. Magnuson;\#10-10 to Jeffrey C. Petruska), Paralyzed Veterans of America (Fellowship \#2579 to Benjamin J. Harrison), and NIH (NS071299 to Jeffrey C. Petruska).

Robinson, J. K. (2006b). Combin treatment with neurotrophin-3 and LSD facilitates behavioral recovinjury in neonatal rats. J. Neurotrauma $23,66-74$.

Arvanian, H. P. VI, Gage, F. H., and Mendell, L. M. (2003). Chronic neurotrophin-3 strengthens synaptic connections to motoneurons in the neonatal rat. J. Neurosci. 23, 8706-8712.

Bao, F., Brown, A., Dekaban, G. A., Omana, V., and Weaver, L. C. (2011). CD11d integrin blockade reduces the systemic inflammatory response syndrome after spinal cord injury. Exp. Neurol. 231, 272-283. and Weaver, L. C. (2004). An antiCD11d integrin antibody reduces cyclooxygenase-2 expression and protein and DNA oxidation after spinal cord injury in rats. J. Neurochem. 90, 1194-1204.

Bao, F., Omana, V., Brown, A., and Weaver, L. C. (2012). The systemic cord injury in the rat is decreased by alpha4betal integrin blockade. $J$. Neurotrauma 29, 1626-1637.

E. T. (2012). Spinal cord injury triggers an intrinsic growth-promoting state in nociceptors. J. Neurotrauma 29, 925-935.

Barbacid, M. (1995). Neurotrophic factors and their receptors. Curr. Opin. Cell Biol. 7, 148-155.

Basso, D. M., Beattie, M. S., and Bresnahan, J. C. (1996). Graded histological and locomotor outcomes after spinal cord contusion using the NYU weight-drop device versus transection. Exp. Neurol. 139, 244-256.

Beattie, M. S., Hermann, G. E., Rogers, R. C., and Bresnahan, J. C. (2002). Cell death in models of spinal cord injury. Prog. Brain Res. 137, 37-47.

Beck, K. D., Nguyen, H. X., Galvan, M. D., Salazar, D. L., Woodruff, T. M., and Anderson, A. J. (2010). Quantitative analysis of cellular inflammation after traumatic spinal cord injury: evidence for a multiphasic inflammatory response in the acute to chronic environment. Brain 133, 433-447.

Bedi, S. S., Lago, M. T., Masha, L. I., Crook, R. J., Grill, R. J., and Walters,
Bedi, S. S., Yang, Q., Crook, R. J., Du, J., Wu, Z., Fishman, H. M., et al. (2010). Chronic spontaneous activity generated in the somata of primary nociceptors is associated with painrelated behavior after spinal cord injury. J. Neurosci. 30, 14870-14882.

Bedogni, B., Pani, G., Colavitti, R., Riccio, A., Borrello, S., Murphy, M., et al. (2003). Redox regulation of cAMPresponsive element-binding protein and induction of manganous superoxide dismutase in nerve growth factor-dependent cell survival. J. Biol. Chem. 278, 16510-16519.

Bender, R. A., Lauterborn, J. C., Gall, C. M., Cariaga, W., and Baram, T. Z. (2001). Enhanced CREB phosphorylation in immature dentate gyrus granule cells precedes neurotrophin expression and indicates a specific role of CREB in granule cell differentiation. Eur. J. Neurosci. 13, 679-686. 
Bennett, D. L., Michael, G. J., Ramachandran, N., Munson, J. B., Averill, S., Yan, Q., et al. (1998). A distinct subgroup of small DRG cells express GDNF receptor components and GDNF is protective for these neurons after nerve injury. $J$. Neurosci. 18, 3059-3072.

Benoit, M. E., and Tenner, A. J. (2011). Complement protein $\mathrm{Clq}$-mediated neuroprotection is correlated with regulation of neuronal gene and microRNA expression. J. Neurosci. 31, 3459-3469.

Bergman, E., Fundin, B. T., and Ulfhake, B. (1999). Effects of aging and axotomy on the expression of neurotrophin receptors in primary sensory neurons. J. Comp. Neurol. 410, 368-386.

Bergman, E., Ulfhake, B., and Fundin, B. T. (2000). Regulation of NGFfamily ligands and receptors in adulthood and senescence: correlation to degenerative and regenerative changes in cutaneous innervation. Eur. J. Neurosci. 12, 2694-2706.

Blits, B., Oudega, M., Boer, G. J., Bartlett Bunge, M., Verhaagen, J. (2003). Adeno-associated viral vector-mediated neurotrophin gene transfer in the injured adult rat spinal cord improves hindlimb function. Neuroscience 118, 271-281.

Boulenguez, P., and Vinay, L. (2009). Strategies to restore motor functions after spinal cord injury. Curr. Opin. Neurobiol. 19, 587-600.

Bouyer, L. J., and Rossignol, S. (1998). The contribution of cutaneous inputs to locomotion in the intact and the spinal cat. Ann. N. Y. Acad. Sci. 860, 508-512.

Bouyer, L. J., and Rossignol, S. (2003). Contribution of cutaneous inputs from the hindpaw to the control of locomotion. II. Spinal cats. J. Neurophysiol. 90, 3640-3653.

Boyce, V. S., Park, J., Gage, F. H., and Mendell, L. M. (2012). Differential effects of brain-derived neurotrophic factor and neurotrophin-3 on hindlimb function in paraplegic rats. Eur. J. Neurosci. 35, 221-232.

Boyce, V. S., Tumolo, M., Fischer, I., Murray, M., and Lemay, M. A. (2007). Neurotrophic factors promote and enhance locomotor recovery in untrained spinalized cats. $J$. Neurophysiol. 98, 1988-1996.

Brandenburger, T., Castoldi, M., Brendel, M., Grievink, H., Schlosser, L., Werdehausen, R., et al. (2012). Expression of spinal cord microRNAs in a rat model of chronic neuropathic pain. Neurosci. Lett. 506, 281-286.
Bregman, B. S., Coumans, J. V., Dai, H. N., Kuhn, P. L., Lynskey, J., McAtee, M., et al. (2002). Transplants and neurotrophic factors increase regeneration and recovery of function after spinal cord injury. Prog. Brain Res. 137, 257-273.

Brown, A., and Weaver, L. C. (2012). The dark side of neuroplasticity. Exp. Neurol. 235, 133-141.

Buck, C. R., Seburn, K. L., and Cope, T. C. (2000). Neurotrophin expression by spinal motoneurons in adult and developing rats. J. Comp. Neurol. 416, 309-318.

Cameron, A. A., Smith, G. M., Randall, D. C., Brown, D. R., and Rabchevsky, A. G. (2006). Genetic manipulation of intraspinal plasticity after spinal cord injury alters the severity of autonomic dysreflexia. J. Neurosci. 26, 2923-2932.

Cameron, A. A., Vansant, G., Wu, W., Carlo, D. J., and Ill, C. R. (2003). Identification of reciprocally regulated gene modules in regenerating dorsal root ganglion neurons and activated peripheral or central nervous system glia. J. Cell. Biochem. 88, 970-985.

Campagnolo, D. I., Bartlett, J. A., and Keller, S. E. (2000). Influence of neurological level on immune function following spinal cord injury: a review. J. Spinal. Cord Med. 23, 121-128.

Canossa, M., Griesbeck, O., Berninger, B., Campana, G., Kolbeck, R., and Thoenen, H. (1997). Neurotrophin release by neurotrophins: implications for activity-dependent neuronal plasticity. Proc. Natl. Acad. Sci. U.S.A. 94, 13279-13286.

Caudle, K. L., Brown, E. H., ShumSiu, A., Burke, D. A., Magnuson, T. S., Voor, M. J., et al. (2011). Hindlimb immobilization in a wheelchair alters functional recovery following contusive spinal cord injury in the adult rat. Neurorehabil. Neural Repair 25, 729-739.

Chen, C. L., Broom, D. C., Liu, Y., de Nooij, J. C., Li, Z., Cen, C., et al. (2006). Runxl determines nociceptive sensory neuron phenotype and is required for thermal and neuropathic pain. Neuron 49, 365-377.

Chen, W. G., Chang, Q., Lin, Y., Meissner, A., West, A. E., Griffith, E. C., et al. (2003). Derepression of BDNF transcription involves calcium-dependent phosphorylation of MeCP2. Science 302, 885-889.

Choi, J. S., Kim, J. A., and Joo, C. K. (2003). Activation of MAPK and CREB by GM1 induces survival of RGCs in the retina with axotomized nerve. Invest. Ophthalmol. Vis. Sci. 44, 1747-1752.

Collazos-Castro, J. E., Soto, V. M., Gutierrez-Davila, M., and NietoSampedro, M. (2005). Motoneuron loss associated with chronic locomotion impairments after spinal cord contusion in the rat. J. Neurotrauma 22, 544-558.

Copray, S., and Kernell, D. (2000). Neurotrophins and trk-receptors in adult rat spinal motoneurons: differences related to cell size but not to 'slow/fast' specialization. Neurosci. Lett. 289, 217-220.

Côté, M. P., Azzam, G. A., Lemay, M. A., Zhukareva, V., and Houlé, J. D. (2011). Activity-dependent increase in neurotrophic factors is associated with an enhanced modulation of spinal reflexes after spinal cord injury. J. Neurotrauma 28, 299-309.

Crown, E. D., Ye, Z., Johnson, K. M., $\mathrm{Xu}, \mathrm{G}$. Y., McAdoo, D. J., and Hulsebosch, C. E. (2006). Increases in the activated forms of ERK $1 / 2$, p38 MAPK, and CREB are correlated with the expression of at level mechanical allodynia following spinal cord injury. Exp. Neurol. 199, 397-407.

Crown, E. D., Ye, Z., Johnson, K. M. $\mathrm{Xu}, \mathrm{G}$. Y., McAdoo, D. J., Westlund, K. N., et al. (2005). Upregulation of the phosphorylated form of CREB in spinothalamic tract cells following spinal cord injury: relation to central neuropathic pain. Neurosci. Lett. 384, 139-144.

Curtis, R., Tonra, J. R., Stark, J. L. Adryan, K. M., Park, J. S., Cliffer, K. D., et al. (1998). Neuronal injury increases retrograde axonal transport of the neurotrophins to spinal sensory neurons and motor neurons via multiple receptor mechanisms. Mol. Cell. Neurosci. 12, 105-118.

de Groat, W. C., and Yoshimura, N. (2009). Afferent nerve regulation of bladder function in health and disease. Handb. Exp. Pharmacol. 91-138.

de Leon, R. D. (2007). Could neurotrophins replace treadmill training as locomotor therapy following spinal cord injury? Focus on "neurotrophic factors promote and enhance locomotor recovery in untrained spinalized cats." J. Neurophysiol. 98, 1845-1846.

De Leon, R. D., Hodgson, J. A., Roy, R. R., and Edgerton, V. R. (1998). Full weight-bearing hindlimb standing following stand training in the adult spinal cat. J. Neurophysiol. 80, 83-91.

De Leon, R. D., Hodgson, J. A., Roy, R. R., and Edgerton, V. R. (1999).
Retention of hindlimb stepping ability in adult spinal cats after the cessation of step training. J. Neurophysiol. 81, 85-94.

Duberley, R. M., Johnson, I. P., Anand, P., Leigh, P. N., and Cairns, N. J. (1997). Neurotrophin-3-like immunoreactivity and Trk C expression in human spinal motoneurones in amyotrophic lateral sclerosis. J. Neurol. Sci. 148, 33-40.

Edgerton, V. R., Courtine, G., Gerasimenko, Y. P., Lavrov, I., Ichiyama, R. M., Fong, A. J., et al. (2008). Training locomotor networks. Brain Res. Rev. 57, 241-254.

Edgerton, V. R., Tillakaratne, N. J., Bigbee, A. J., de Leon, R. D., and Roy, R. R. (2004). Plasticity of the spinal neural circuitry after injury. Annu. Rev. Neurosci. 27, 145-167.

Edwards-Beckett, J., and King, $\mathrm{H}$. (1996). The impact of spinal pathology on bowel control in children. Rehabil. Nurs. 21, 292-297.

Elkabes, S., Peng, L., and Black, I. B. (1998). Lipopolysaccharide differentially regulates microglial trk receptor and neurotrophin expression. J. Neurosci. Res. 54, 117-122.

Ernfors, P., Rosario, C. M., Merlio, J. P., Grant, G., Aldskogius, H., and Persson, H. (1993). Expression of mRNAs for neurotrophin receptors in the dorsal root ganglion and spinal cord during development and following peripheral or central axotomy. Brain Res. Mol. Brain Res. 17, 217-226.

Farrell, B. C., Power, E. M., and Mc Dermott, K.W. (2011). Developmentally regulated expression of Sox9 and microRNAs 124, 128 and 23 in neuroepithelial stem cells in the developing spinal cord. Int. J. Dev. Neurosci. 29, 31-36.

Ferguson, A. R., Huie, J. R., Crown, E. D., Baumbauer, K. M., Hook, M. A., Garraway, S. M., et al. (2012a). Maladaptive spinal plasticity opposes spinal learning and recovery in spinal cord injury. Front. Physiol. 3:399. doi:10.3389/fphys.2012.00399

Ferguson, A. R., Huie, J. R., Crown, E. D., and Grau, J. W. (2012b) Central nociceptive sensitization vs. spinal cord training: opposing forms of plasticity that dictate function after complete spinal cord injury. Front. Physiol. 3:396. doi:10.3389/fphys.2012.00396

Fleming, J. C., Norenberg, M. D., Ramsay, D. A., Dekaban, G. A., Marcillo, A. E., Saenz, A. D., et al. (2006). The cellular inflammatory response in human spinal cords after injury. Brain 129, 3249-3269. 
Frigon, A., and Rossignol, S. (2009). Partial denervation of ankle extensors prior to spinalization in cats impacts the expression of locomotion and the phasic modulation of reflexes. Neuroscience 158, 1675-1690.

Funakoshi, H., Frisen, J., Barbany, G., Timmusk, T., Zachrisson, O., Verge, V. M., et al. (1993). Differential expression of mRNAs for neurotrophins and their receptors after axotomy of the sciatic nerve. J. Cell Biol. 123, 455-465.

Galoyan, S. M., Petruska, J. C., and Mendell, L. M. (2003). Mechanisms of sensitization of the response of single dorsal root ganglion cells from adult rat to noxious heat. Eur. J. Neurosci. 18, 535-541.

García-Alías, G., Petrosyan, H. A., Schnell, L., Horner, P. J., Bowers, W. J., Mendell, L. M., et al. (2011). Chondroitinase $\mathrm{ABC}$ combined with neurotrophin NT-3 secretion and NR2D expression promotes axonal plasticity and functional recovery in rats with lateral hemisection of the spinal cord. J. Neurosci. 31, 17788-17799.

Garcia-Alias, G., Valero-Cabre, A., Lopez-Vales, R., Fores, J., Verdu, E., and Navarro, X. (2006). Differential motor and electrophysiological outcome in rats with mid-thoracic or high lumbar incomplete spinal cord injuries. Brain Res. 1108, 195-204.

Garraway, S. M., Anderson, A. J., and Mendell, L. M. (2005). BDNFinduced facilitation of afferentevoked responses in lamina II neurons is reduced after neonatal spinal cord contusion injury. J. Neurophysiol. 94, 1798-1804.

Garraway, S. M., and Mendell, L. M. (2007). Spinal cord transection enhances afferent-evoked inhibition in lamina II neurons and abolishes BDNF-induced facilitation of their sensory input. J. Neurotrauma 24, 379-390.

Garraway, S. M., Petruska, J. C., and Mendell, L. M. (2003). BDNF sensitizes the response of lamina II neurons to high threshold primary afferent inputs. Eur. J. Neurosci. 18, 2467-2476.

Garstang, S. V., and Miller-Smith, S. A. (2007). Autonomic nervous system dysfunction after spinal cord injury. Phys. Med. Rehabil. Clin. N. Am. 18, 275-296, vi-vii.

Gibbons, A. S., and Bailey, K. A. (2005). BDNF and NT-3 regulation of trkB and trkC mRNA levels in the developing chick spinal cord. Neurosci. Lett. 385, 41-45.

Gomez-Pinilla, F., Ying, Z., Roy, R. R., Hodgson, J., and Edgerton, V. R.
(2004). Afferent input modulates neurotrophins and synaptic plasticity in the spinal cord. J. Neurophysiol. 92, 3423-3432.

Gratto, K. A., and Verge, V. M. (2003). Neurotrophin-3 down-regulates trkA mRNA, NGF high-affinity binding sites, and associated phenotype in adult DRG neurons. Eur. J. Neurosci. 18, 1535-1548.

Grau, J. W., Huie, J. R., Garraway, S. M., Hook, M. A., Crown, E. D., Baumbauer, K. M., et al. (2012). Impact of behavioral control on the processing of nociceptive stimulation. Front. Physiol. 3:262. doi:10.3389/fphys.2012.00262

Grau, J. W., Washburn, S. N., Hook, M. A., Ferguson, A. R., Crown, E. D., Garcia, G., et al. (2004). Uncontrollable stimulation undermines recovery after spinal cord injury. J. Neurotrauma 21, 1795-1817.

Grimson, A., Farh, K. K., Johnston, W. K., Garrett-Engele, P., Lim, L. P., and Bartel, D. P. (2007). MicroRNA targeting specificity in mammals: determinants beyond seed pairing. Mol. Cell 27, 91-105.

Gris, D., Hamilton, E. F., and Weaver, L. C. (2008). The systemic inflammatory response after spinal cord injury damages lungs and kidneys. Exp. Neurol. 211, 259-270.

Guidi, M., Muinos-Gimeno, M., Kagerbauer, B., Marti, E., Estivill, X., and Espinosa-Parrilla, Y. (2010). Overexpression of miR-128 specifically inhibits the truncated isoform of NTRK3 and upregulates BCL2 in SH-SY5Y neuroblastoma cells. BMC Mol. Biol. 11:95. doi:10.1186/14712199-11-95

Gulino, R., Lombardo, S. A., Casabona, A., Leanza, G., and Perciavalle, V. (2004). Levels of brain-derived neurotrophic factor and neurotrophin-4 in lumbar motoneurons after lowthoracic spinal cord hemisection. Brain Res. 1013, 174-181.

Guth, L., Zhang, Z., DiProspero, N. A., Joubin, K., and Fitch, M. T. (1994). Spinal cord injury in the rat: treatment with bacterial lipopolysaccharide and indomethacin enhances cellular repair and locomotor function. Exp. Neurol. 126, 76-87.

Hajebrahimi, Z., Mowla, S. J., Movahedin, M., and Tavallaei, M. (2008). Gene expression alterations of neurotrophins, their receptors and prohormone convertases in a rat model of spinal cord contusion. Neurosci. Lett. 441, 261-266.

Hamada, N., Fujita, Y., Kojima, T., Kitamoto, A., Akao, Y., Nozawa, Y., et al. (2012). MicroRNA expression profiling of NGF-treated PC12 cells revealed a critical role for $\mathrm{miR}$ 221 in neuronal differentiation. $\mathrm{Neu}$ rochem. Int. 60, 743-750.

Harkema, S. J. (2008). Plasticity of interneuronal networks of the functionally isolated human spinal cord. Brain Res. Rev. 57, 255-264.

Hayashi, M., Ueyama, T., Nemoto, K. Tamaki, T., and Senba, E. (2000). Sequential mRNA expression for immediate early genes, cytokines, and neurotrophins in spinal cord injury. J. Neurotrauma 17, 203-218.

He, Q., Csiszar, K., and Li, P. (2003). Transient forebrain ischemia induced phosphorylation of CAMPresponsive element-binding protein is suppressed by hyperglycemia. Neurobiol. Dis. 12, 25-34.

Hess, D. M., Scott, M. O., Potluri, S., Pitts, E. V., Cisterni, C., and BaliceGordon, R. J. (2007). Localization of TrkC to Schwann cells and effects of neurotrophin-3 signaling at neuromuscular synapses. J. Comp. Neurol. 501, 465-482.

Hill, C. E., Harrison, B. J., Rau, K. K., Hougland, M. T., Bunge, M. B., Mendell, L. M., et al. (2010). Skin incision induces expression of axonal regeneration-related genes in adult rat spinal sensory neurons. $J$. Pain. 11, 1066-1073.

Howe, E. N., Cochrane, D. R., and Richer, J. K. (2011). Targets of miR-200c mediate suppression of cell motility and anoikis resistance. Breast Cancer Res. 13, R45.

Huang, E. J., and Reichardt, L. F. (2001) Neurotrophins: roles in neuronal development and function. Annu. Rev. Neurosci. 24, 677-736.

Huang, E. J., and Reichardt, L. F. (2003). Trk receptors: roles in neuronal signal transduction. Annu. Rev. Biochem. 72, 609-642.

Huang, W. L., Robson, D., Liu, M. C., King, V. R., Averill, S., Shortland, P. J., et al. (2006). Spinal cord compression and dorsal root injury cause upregulation of activating transcription factor-3 in large-diameter dorsal root ganglion neurons. Eur. J. Neurosci. 23, 273-278.

Hutchinson, K. J., Gómez-Pinilla, F., Crowe, M. J., Ying, Z., and Basso, D. M. (2004). Three exercise paradigms differentially improve sensory recovery after spinal cord contusion in rats. Brain 127, 1403-1414.

Inoue, K., Ozaki, S., Shiga, T., Ito, K. Masuda, T., Okado, N., et al. (2002). Runx3 controls the axonal projection of proprioceptive dorsal root ganglion neurons. Nat. Neurosci. 5, 946-954.

Ivanavicius, S. P., Ball, A. D., Heapy, C. G., Westwood, F. R., Murray,
F., and Read, S. J. (2007). Structural pathology in a rodent model of osteoarthritis is associated with neuropathic pain: increased expression of ATF- 3 and pharmacological characterisation. Pain 128, 272-282.

Ji, R. R., and Rupp, F. (1997). Phosphorylation of transcription factor CREB in rat spinal cord after formalin-induced hyperalgesia: relationship to c-fos induction. $\mathrm{J}$. $\mathrm{Neu}$ rosci. 17, 1776-1785.

Jin, W., Lee, J. J., Kim, M. S., Son, B. H., Cho, Y. K., and Kim, H. P. (2011). DNA methylation-dependent regulation of TrkA, TrkB, and TrkC genes in human hepatocellular carcinoma. Biochem. Biophys. Res. Commun. 406, 89-95.

Josephson, A., Widenfalk, J., Trifunovski, A., Widmer, H. R., Olson, L., and Spenger, C. (2001). GDNF and NGF family members and receptors in human fetal and adult spinal cord and dorsal root ganglia. J. Comp. Neurol. 440, 204-217.

Kawahara, H., Imai, T., and Okano, H. (2012). MicroRNAs in neural stem cells and neurogenesis. Front. Neurosci. 6:30. doi:10.3389/ fnins.2012.00030

Kawahara, H., Okada, Y., Imai, T., Iwanami, A., Mischel, P. S., and Okano, H. (2011). Musashil cooperates in abnormal cell lineage protein 28 ( $\operatorname{Lin} 28)$-mediated let-7 family microRNA biogenesis in early neural differentiation. J. Biol. Chem. 286, 16121-16130.

Keeler, B. E., Liu, G., Siegfried, R. N., Zhukareva, V., Murray, M., and Houlé, J. D. (2012). Acute and prolonged hindlimb exercise elicits different gene expression in motoneurons than sensory neurons after spinal cord injury. Brain Res. 8-21.

Kerr, B. J., Bradbury, E. J., Bennett, D. L., Trivedi, P. M., Dassan, P., French, J., et al. (1999). Brain-derived neurotrophic factor modulates nociceptive sensory inputs and NMDAevoked responses in the rat spinal cord. J. Neurosci. 19, 5138-5148.

Kigerl, K. A., McGaughy, V. M., and Popovich, P. G. (2006). Comparative analysis of lesion development and intraspinal inflammation in four strains of mice following spinal contusion injury. J. Comp. Neurol. 494, 578-594.

Kim, C. F., and Moalem-Taylor, G. (2011). Detailed characterization of neuro-immune responses following neuropathic injury in mice. Brain Res. 1405, 95-108.

Klein, R., Silos-Santiago, I., Smeyne, R. J., Lira, S. A., Brambilla, R., and Bryant, S. (1994). Disruption of 
the neurotrophin-3 receptor gene trkC eliminates la muscle afferents and results in abnormal movements. Nature 368, 249-251.

Kobayashi, A., Tsukide, T., Miyasaka, T., Morita, T., Mizoroki, T., Saito, Y., et al. (2011). Central nervous systemspecific deletion of transcription factor Nrf1 causes progressive motor neuronal dysfunction. Genes Cells 16, 692-703.

Kosik, K. S., and Krichevsky, A. M. (2005). The elegance of the MicroRNAs: a neuronal perspective. Neuron 47, 779-782.

Krassioukov, A. V., and Fehlings, M. G. (1999). Effect of graded spinal cord compression on cardiovascular neurons in the rostro-ventro-lateral medulla. Neuroscience 88, 959-973.

Krekoski, C. A., Parhad, I. M., and Clark, A. W. (1996). Attenuation and recovery of nerve growth factor receptor mRNA in dorsal root ganglion neurons following axotomy. J. Neurosci. Res. 43, 1-11.

Krenz, N. R., Meakin, S. O., Krassioukov, A. V., and Weaver, L. C. (1999). Neutralizing intraspinal nerve growth factor blocks autonomic dysreflexia caused by spinal cord injury. J. Neurosci. 19, 7405-7414.

Kuo, L. T., Groves, M. J., Scaravilli, F., Sugden, D., An, S. F. (2007). Neurotrophin-3 administration alters neurotrophin, neurotrophin receptor and nestin mRNA expression in rat dorsal root ganglia following axotomy. Neuroscience 147, 491-507.

Kwon, B. K., Stammers, A. M., Belanger, L. M., Bernardo, A., Chan, D., Bishop, C. M., et al. (2010). Cerebrospinal fluid inflammatory cytokines and biomarkers of injury severity in acute human spinal cord injury. J. Neurotrauma 27, 669-682.

Lee, P., Zhuo, H., and Helke, C. J. (2001). Axotomy alters neurotrophin and neurotrophin receptor mRNAs in the vagus nerve and nodose ganglion of the rat. Brain Res. Mol. Brain Res. $87,31-41$.

Leingärtner, A., Heisenberg, C. P., Kolbeck, R., Thoenen, H., and Lindholm, D. (1994). Brain-derived neurotrophic factor increases neurotrophin-3 expression in cerebellar granule neurons. J. Biol. Chem. 269, 823-830.

Levanon, D., Bettoun, D., HarrisCerruti, C., Woolf, E., Negreanu, V., Eilam, R., et al. (2002). The Runx3 transcription factor regulates development and survival of TrkC dorsal root ganglia neurons. EMBO J. 21, 3454-3463.
Lewin, G. R. (1996). Neurotrophins and the specification of neuronal phenotype. Philos. Trans. R. Soc. Lond. B Biol. Sci. 351, 405-411.

Li, X. L., Zhang, W., Zhou, X., Wang, X. Y., Zhang, H. T., Qin, D. X., et al. (2007). Temporal changes in the expression of some neurotrophins in spinal cord transected adult rats. Neuropeptides 41, 135-143.

Liebl, D. J., Huang, W., Young, W., and Parada, L. F. (2001). Regulation of Trk receptors following contusion of the rat spinal cord. Exp. Neurol. 167, 15-26.

Lindsay, R. M. (1996). Role of neurotrophins and trk receptors in the development and maintenance of sensory neurons: an overview. Philos. Trans. R. Soc. Lond. B Biol. Sci. 351, 365-373.

Lubieniecka, J. M., Streijger, F., Lee, J. H., Stoynov, N., Liu, J., Mottus, R., et al. (2011). Biomarkers for severity of spinal cord injury in the cerebrospinal fluid of rats. PLoS ONE 6:e19247. doi:10.1371/journal.pone.0019247

Lucin, K. M., Sanders, V. M., Jones, T. B., Malarkey, W. B., and Popovich, P. G. (2007). Impaired antibody synthesis after spinal cord injury is level dependent and is due to sympathetic nervous system dysregulation. Exp. Neurol. 207, 75-84.

Lynch, A. C., Anthony, A., Dobbs, B. R., and Frizelle, F. A. (2000). Anorectal physiology following spinal cord injury. Spinal Cord 38, 573-580.

Ma, W. Y., Murata, E., Ueda, K., Kuroda, Y., Cao, M. H., Abe, M., et al. (2010). A synthetic cell-penetrating peptide antagonizing TrkA function suppresses neuropathic pain in mice. J. Pharmacol. Sci. 114, 79-84.

Machiya, J., Shibata, Y., Yamauchi, K., Hirama, N., Wada, T., Inoue, S., et al. (2007). Enhanced expression of MafB inhibits macrophage apoptosis induced by cigarette smoke exposure. Am. J. Respir. Cell Mol. Biol. 36, 418-426.

Magnuson, D. S., Lovett, R., Coffee, C., Gray, R., Han, Y., Zhang, Y. P., et al. (2005). Functional consequences of lumbar spinal cord contusion injuries in the adult rat. $J$. Neurotrauma 22, 529-543.

Magnuson, D. S., Trinder, T. C., Zhang, Y. P., Burke, D., Morassutti, D. J., and Shields, C. B. (1999). Comparing deficits following excitotoxic and contusion injuries in the thoracic and lumbar spinal cord of the adult rat. Exp. Neurol. 156, 191-204.
Maiorov, D. N., Fehlings, M. G., and Krassioukov, A. V. (1998). Relationship between severity of spinal cord injury and abnormalities in neurogenic cardiovascular control in conscious rats. J. Neurotrauma 15 , 365-374.

Mallei, A., Rabin, S. J., and Mocchetti, I. (2004). Autocrine regulation of nerve growth factor expression by Trk receptors. J. Neurochem. 90, 1085-1093.

Mantyh, P. W., Koltzenburg, M. Mendell, L. M., Tive, L., and Shelton, D. L. (2011). Antagonism of nerve growth factor-TrkA signaling and the relief of pain. Anesthesiology 115, 189-204.

Marsh, D. R., Wong, S. T., Meakin, S. O. MacDonald, J. I., Hamilton, E. F., and Weaver, L. C. (2002). Neutralizing intraspinal nerve growth factor with a trkA-IgG fusion protein blocks the development of autonomic dysreflexia in a clip-compression model of spinal cord injury. J. Neurotrauma 19, 1534-1541.

Massey, J. M., Hubscher, C. H., Wagoner, M. R., Decker, J. A., Amps, J., Silver, J., et al. (2006). Chondroitinase $\mathrm{ABC}$ digestion of the perineuronal net promotes functional collateral sprouting in the cuneate nucleus after cervical spinal cord injury. J. Neurosci. 26, 4406-4414.

McMahon, S. B. (1996). NGF as a mediator of inflammatory pain. Philos. Trans. R. Soc. Lond. B Biol. Sci. 351, 431-440.

McMahon, S. B., Armanini, M. P., Ling, L. H., and Phillips, H. S. (1994). Expression and coexpression of Trk receptors in subpopulations of adult primary sensory neurons projecting to identified peripheral targets. Neuron 12, 1161-1171.

Mendell, L. M., Munson, J. B., and Arvanian, V. L. (2001). Neurotrophins and synaptic plasticity in the mammalian spinal cord. $J$. Physiol. (Lond.) 533, 91-97.

Michael, G. J., Averill, S., Nitkunan, A. Rattray, M., Bennett, D. L., Yan, Q., et al. (1997). Nerve growth factor treatment increases brain-derived neurotrophic factor selectively in TrkAexpressing dorsal root ganglion cells and in their central terminations within the spinal cord. J. Neurosci. 17, 8476-8490.

Molliver, D. C., and Snider, W. D. (1997). Nerve growth factor receptor TrkA is down-regulated during postnatal development by a subset of dorsal root ganglion neurons. J. Comp. Neurol. 381, 428-438.

Moon, L., and Bunge, M. B. (2005). From animal models to humans: strategies for promoting CNS axon regeneration and recovery of limb function after spinal cord injury. $J$. Neurol. Phys. Ther. 29, 55-69.

$\mathrm{Mu}, \quad$ X., Silos-Santiago, I., Carroll, S. L., and Snider, W. D. (1993). Neurotrophin receptor genes are expressed in distinct patterns in developing dorsal root ganglia. J. Neurosci. 13, 4029-4041.

Nakamura, M., and Bregman, B. S. (2001). Differences in neurotrophic factor gene expression profiles between neonate and adult rat spinal cord after injury. Exp. Neurol. 169, 407-415

Nakatani, T., Ueno, S., Mori, N., and Matsuoka, I. (2005). Role of NRSF/REST in the molecular mechanisms regulating neural-specific expression of trkC/neurotrophin-3 receptor gene. Brain Res. Mol. Brain Res. 135, 249-259.

Nassenstein, C., Kerzel, S., and Braun, A. (2004). Neurotrophins and neurotrophin receptors in allergic asthma. Prog. Brain Res. 146, 347-367.

Natera-Naranjo, O., Aschrafi, A., Gioio, A. E., and Kaplan, B. B. (2010) Identification and quantitative analyses of microRNAs located in the distal axons of sympathetic neurons. RNA 16, 1516-1529.

Nemoto, K., Fukamachi, K., Nemoto, F., Miyata, S., Hamada, M., Nakamura, Y., et al. (1998). Gene expression of neurotrophins and their receptors in cultured rat vascular smooth muscle cells. Biochem. Biophys. Res. Commun. 245, 284-288.

Ng, M. T., Stammers, A. T., and Kwon, B. K. (2011). Vascular disruption and the role of angiogenic proteins after spinal cord injury. Transl. Stroke Res. 2, 474-491.

Nguyen, H. X., O'Barr, T. J., and Anderson, A. J. (2007). Polymorphonuclear leukocytes promote neurotoxicity through release of matrix metalloproteinases, reactive oxygen species, and TNF-alpha. J. Neurochem. 102, 900-912.

Noga, O., Englmann, C., Hanf, G., Grutzkau, A., Guhl, S., and Kunkel, G. (2002). Activation of the specific neurotrophin receptors TrkA, TrkB and TrkC influences the function of eosinophils. Clin. Exp. Allergy 32, 1348-1354.

Nosrat, C. A. (1998). Neurotrophic factors in the tongue: expression patterns, biological activity, relation to innervation and studies of neurotrophin knockout mice. Ann. N. Y. Acad. Sci. 855, 28-49.

Oakley, R. A., Lefcort, F. B., Clary, D. O., Reichardt, L. F., Prevette, D., 
Oppenheim, R. W., et al. (1997). Neurotrophin-3 promotes the differentiation of muscle spindle afferents in the absence of peripheral targets. J. Neurosci. 17, 4262-4274.

Obata, K., Yamanaka, H., Dai, Y., Mizushima, T., Fukuoka, T., Tokunaga, A., et al. (2004). Activation of extracellular signal-regulated protein kinase in the dorsal root ganglion following inflammation near the nerve cell body. Neuroscience 126, 1011-1021.

Ollivier-Lanvin, K., Keeler, B. E., Siegfried, R., Houle, J. D., and Lemay, M. A. (2010). Proprioceptive neuropathy affects normalization of the H-reflex by exercise after spinal cord injury. Exp. Neurol. 221, 198-205.

Otten, U., Marz, P., Heese, K., Hock, C., Kunz, D., and Rose-John, S. (2000). Cytokines and neurotrophins interact in normal and diseased states. Ann. N. Y. Acad. Sci. 917, 322-330.

Patapoutian, A., and Reichardt, L. F. (2001). Trk receptors: mediators of neurotrophin action. Curr. Opin. Neurobiol. 11, 272-280.

Petruska, J. C., Ichiyama, R. M., Jindrich, D. L., Crown, E. D., Tansey, K. E., Roy, R. R., et al. (2007). Changes in motoneuron properties and synaptic inputs related to step training after spinal cord transection in rats. J. Neurosci. 27, 4460-4471.

Petruska, J. C., Kitay, B., Boyce, V. S., Kaspar, B. K., Pearse, D. D., Gage, F. H., et al. (2010). Intramuscular AAV delivery of NT-3 alters synaptic transmission to motoneurons in adult rats. Eur. J. Neurosci. 32, 997-1005.

Petruska, J. C., and Mendell, L. M. (2004). The many functions of nerve growth factor: multiple actions on nociceptors. Neurosci. Lett. 361, 168-171.

Phillips, H. S., and Armanini, M. P. (1996). Expression of the trk family of neurotrophin receptors in developing and adult dorsal root ganglion neurons. Philos. Trans. R. Soc. Lond. B Biol. Sci. 351, 413-416.

Popovich, P. G. (2000). Immunological regulation of neuronal degeneration and regeneration in the injured spinal cord. Prog. Brain Res. 128, 43-58.

Popovich, P. G., Stuckman, S., Gienapp, I. E., and Whitacre, C. C. (2001). Alterations in immune cell phenotype and function after experimental spinal cord injury. J. Neurotrauma 18, 957-966.

Popovich, P. G., Wei, P., and Stokes, B. T. (1997). Cellular inflammatory response after spinal cord injury in
Sprague-Dawley and Lewis rats. J. Comp. Neurol. 377, 443-464.

Profyris, C., Cheema, S. S., Zang, D., Azari, M. F., Boyle, K., and Petratos, S. (2004). Degenerative and regenerative mechanisms governing spinal cord injury. Neurobiol. Dis. 15, 415-436.

Qian, D. X., Zhang, H. T., Cai, Y. Q., Luo, P., and Xu, R. X. (2011). Expression of tyrosine kinase receptor $\mathrm{C}$ in the segments of the spinal cord and the cerebral cortex after cord transection in adult rats. Neurosci. Bull. 27, 83-90.

Qiao, L., and Vizzard, M. A. (2002). Upregulation of tyrosine kinase (Trka, Trkb) receptor expression and phosphorylation in lumbosacral dorsal root ganglia after chronic spinal cord (T8-T10) injury. J. Comp. Neurol. 449, 217-230.

Qiao, L. Y., and Vizzard, M. A. (2005). Spinal cord injury-induced expression of TrkA, TrkB, phosphorylated CREB, and c-Jun in rat lumbosacral dorsal root ganglia. J. Comp. Neurol. 482, 142-154.

Qin, D. X., Zou, X. L., Luo, W. Zhang, W., Zhang, H. T., Li, X. L., et al. (2006). Expression of some neurotrophins in the spinal motoneurons after cord hemisection in adult rats. Neurosci. Lett. 410, 222-227.

Rabchevsky, A. G., Sullivan, P. G., and Scheff, S. W. (2007). Temporalspatial dynamics in oligodendrocyte and glial progenitor cell numbers throughout ventrolateral white matter following contusion spinal cord injury. Glia 55, 831-843.

Rau, C. S., Jeng, J. C., Jeng, S. F., Lu, T. H., Chen, Y. C., Liliang, P. C., et al. (2010). Entrapment neuropathy results in different microRNA expression patterns from denervation injury in rats. BMC Musculoskelet. Disord. 11:181. doi:10.1186/1471-2474-11-181

Reichardt, L. F. (2006). Neurotrophinregulated signalling pathways. Philos. Trans. R. Soc. Lond. B Biol. Sci. 361, 1545-1564.

Rossignol, S. (2006). Plasticity of connections underlying locomotor recovery after central and/or peripheral lesions in the adult mammals. Philos. Trans. R. Soc. Lond. B Biol. Sci. 361, 1647-1671.

Rossignol, S., and Frigon, A. (2011). Recovery of locomotion after spinal cord injury: some facts and mechanisms. Annu. Rev. Neurosci. 34, 413-440.

Ryan, J., Tivnan, A., Fay, J., Bryan, K., Meehan, M., Creevey, L., et al. (2012). MicroRNA-204 increases sensitivity of neuroblastoma cells to cisplatin and is associated with a favourable clinical outcome. $\mathrm{Br}$. J. Cancer 107, 967-976.

Saba, R., Goodman, C. D., Huzarewich, R. L., Robertson, C., and Booth, S. A. (2008). A miRNA signature of prion induced neurodegeneration. PLoS ONE 3:e3652. doi:10.1371/journal.pone.0003652

Schnell, L., Hunanyan, A. S., Bowers, W. J., Horner, P. J., Federoff, H. J., Gullo, M., et al. (2011). Combined delivery of Nogo-A antibody, neurotrophin3 and the NMDA-NR2d subunit establishes a functional 'detour' in the hemisected spinal cord. Eur. J. Neurosci. 34, 1256-1267.

Schober, A., Wolf, N., Kahane, N., Kalcheim, C., Krieglstein, K., and Unsicker, K. (1999). Expression of neurotrophin receptors $\operatorname{trkB}$ and trkC and their ligands in rat adrenal gland and the intermediolateral column of the spinal cord. Cell Tissue Res. 296, 271-279.

Schucht, P., Raineteau, O., Schwab, M. E., and Fouad, K. (2002). Anatomical correlates of locomotor recovery following dorsal and ventral lesions of the rat spinal cord. Exp. Neurol. 176, 143-153.

Sebert, M. E., and Shooter, E. M. (1993). Expression of mRNA for neurotrophic factors and their receptors in the rat dorsal root ganglion and sciatic nerve following nerve injury. J. Neurosci. Res. 36, 357-367.

Sharma, H., Alilain, W. J., Sadhu, A., and Silver, J. (2012). Treatments to restore respiratory function after spinal cord injury and their implications for regeneration, plasticity and adaptation. Exp. Neurol. 235, 18-25.

Shu, X., and Mendell, L. M. (1999). Nerve growth factor acutely sensitizes the response of adult rat sensory neurons to capsaicin. Neurosci. Lett. 274, 159-162.

Shu, X., and Mendell, L. M. (2001). Acute sensitization by NGF of the response of small-diameter sensory neurons to capsaicin. J. Neurophysiol. 86, 2931-2938.

Shu, X. Q., Llinas, A., and Mendell, L. M. (1999). Effects of trkB and trkC neurotrophin receptor agonists on thermal nociception: a behavioral and electrophysiological study. Pain 80 , 463-470.

Skaper, S. D. (2008). The biology of neurotrophins, signalling pathways, and functional peptide mimetics of neurotrophins and their receptors. CNS Neurol. Disord. Drug Targets 7, 46-62.

Skaper, S. D. (2012). The neurotrophin family of neurotrophic factors: an overview. Methods Mol. Biol. 846, $1-12$.

Smith, B., Treadwell, J., Zhang, D., Ly, D., McKinnell, I., Walker, P. R., et al. (2010). Large-scale expression analysis reveals distinct microRNA profiles at different stages of human neurodevelopment. PLOS ONE 5:e11109. doi:10.1371/journal.pone.0011109

Smith, G. M., Falone, A. E., and Frank, E. (2012). Sensory axon regeneration: rebuilding functional connections in the spinal cord. Trends Neurosci. 35, 156-163.

Smith, R. R., Burke, D. A., Baldini, A. D., Shum-Siu, A., Baltzley, R., Bunger, M., et al. (2006). The Louisville Swim Scale: a novel assessment of hindlimb function following spinal cord injury in adult rats. J. Neurotrauma 23, 1654-1670.

Sroga, J. M., Jones, T. B., Kigerl, K. A., McGaughy, V. M., and Popovich, P. G. (2003). Rats and mice exhibit distinct inflammatory reactions after spinal cord injury. J. Comp. Neurol. 462, 223-240.

Stam, F. J., MacGillavry, H. D., Armstrong, N. J., De Gunst, M. C., Zhang, Y., Van Kesteren, R. E., et al. (2007). Identification of candidate transcriptional modulators involved in successful regeneration after nerve injury. Eur. J. Neurosci. 25, 3629-3637.

Stammers, A. T., Liu, J., and Kwon, B. K. (2012). Expression of inflammatory cytokines following acute spinal cord injury in a rodent model. $J$. Neurosci. Res. 90, 782-790.

Strube, C., Buschbaum, S., Wolken, S. and Schnieder, T. (2008). Evaluation of reference genes for quantitative real-time PCR to investigate protein disulfide isomerase transcription pattern in the bovine lungworm Dictyocaulus viviparus. Gene 425, 36-43.

Suarez, V., Guntinas-Lichius, O., Streppel, M., Ingorokva, S., Grosheva, M., Neiss, W. F., et al. (2006). The axotomy-induced neuropeptides galanin and pituitary adenylate cyclase-activating peptide promote axonal sprouting of primary afferent and cranial motor neurones. Eur. J. Neurosci. 24, 1555-1564.

Tabakman, R., Lecht, S., Sephanova, S., Arien-Zakay, H., and Lazarovici, P. (2004). Interactions between the cells of the immune and nervous system: neurotrophins as neuroprotection mediators in CNS injury. Prog. Brain Res. 146, 387-401.

Tacconelli, A., Farina, A. R., Cappabianca, L., Gulino, A., and Mackay, A. R. (2005). TrkAIII. A novel 
hypoxia-regulated alternative TrkA splice variant of potential physiological and pathological importance. Cell Cycle 4, 8-9.

Tai, C., Roppolo, J. R., and De Groat, W. C. (2006). Spinal reflex control of micturition after spinal cord injury. Restor. Neurol. Neurosci. 24, 69-78.

Tao, X., Finkbeiner, S., Arnold, D. B., Shaywitz, A. J., and Greenberg, M. E. (1998). Ca2+ influx regulates BDNF transcription by a CREB family transcription factor-dependent mechanism. Neuron 20, 709-726.

Tao, X., West, A. E., Chen, W. G., Corfas, G., and Greenberg, M. E. (2002). A calcium-responsive transcription factor, CaRF, that regulates neuronal activity-dependent expression of BDNF. Neuron 33, 383-395.

Thakur, M., Rahman, W., Hobbs, C., Dickenson, A. H., and Bennett, D. L. (2012). Characterisation of a peripheral neuropathic component of the rat monoiodoacetate model of osteoarthritis. PLoS ONE 7:e33730. doi:10.1371/journal.pone.0033730

Timmusk, T., Belluardo, N., Persson, H., and Metsis, M. (1994). Developmental regulation of brainderived neurotrophic factor messenger RNAs transcribed from different promoters in the rat brain. Neuroscience 60, 287-291.

Ung, R. V., Lapointe, N. P., and Guertin, P. A. (2008). Early adaptive changes in chronic paraplegic mice: a model to study rapid health degradation after spinal cord injury. Spinal Cord 46, 176-180.

Vega-Avelaira, D., Geranton, S. M., and Fitzgerald, M. (2009). Differential regulation of immune responses and macrophage/neuron interactions in the dorsal root ganglion in young and adult rats following nerve injury. Mol. Pain 5, 70.

Vizzard, M. A. (2000). Changes in urinary bladder neurotrophic factor mRNA and NGF protein following urinary bladder dysfunction. Exp. Neurol. 161, 273-284.

Vogelaar, C. F., Hoekman, M. F., Brakkee, J. H., Bogerd, J., and Burbach, J. P. (2004). Developmental regulation of homeobox gene expression in dorsal root ganglion neurons is not recapitulated during regeneration of the crushed sciatic nerve. Neuroscience 125, 645-650.

Walters, E. T. (2012). Nociceptors as chronic drivers of pain and hyperreflexia after spinal cord injury: an adaptive-maladaptive hyperfunctional state hypothesis. Front. Physiol. 3:309. doi:10.3389/ fphys.2012.00309

Wang, F., Liu, W., Ma, J., Yu, M., Jin, Y., and Dai, J. (2012). Prenatal and neonatal exposure to perfluorooctane sulfonic acid results in changes in miRNA expression profiles and synapse associated proteins in developing rat brains. Environ. Sci. Technol. 46, 6822-6829.

Weaver, L. C., Cassam, A. K., Krassioukov, A. V., and LlewellynSmith, I. J. (1997). Changes in immunoreactivity for growth associated protein-43 suggest reorganization of synapses on spinal sympathetic neurons after cord transection. Neuroscience 81, 535-551.

Wernig, A., Müller, S., Nanassy, A., and Cagol, E. (1995). Laufband therapy based on 'rules of spinal locomotion' is effective in spinal cord injured persons. Eur. J. Neurosci. 7, 823-829.

Wetmore, C., and Olson, L. (1995). Neuronal and nonneuronal expression of neurotrophins and their receptors in sensory and sympathetic ganglia suggest new intercellular trophic interactions. J. Comp. Neurol. 353, 143-159.

Widenfalk, J., Lundströmer, K., Jubran, M., Brene, S., and Olson, L. (2001). Neurotrophic factors and receptors in the immature and adult spinal cord after mechanical injury or kainic acid. J. Neurosci. 21, 3457-3475.

Widenfalk, J., Olson, L., and Thoren, P. (1999). Deprived of habitual running, rats downregulate BDNF and TrkB messages in the brain. Neurosci. Res. 34, 125-132.

Wingender, E. (2008). The TRANSFAC project as an example of framework technology that supports the analysis of genomic regulation. Brief. Bioinformatics 9, 326-332.
Wingender, E., Chen, X., Hehl, R., Karas, H., Liebich, I., Matys, V. et al. (2000). TRANSFAC: an integrated system for gene expression regulation. Nucleic Acids Res. 28 316-319.

Wright De, S. W. (1995). Neurotrophin receptor mRNA expression defines distinct populations of neurons in rat dorsal root ganglia. J. Comp. Neurol. 351, 329-338.

Wyatt, S., Middleton, G., Doxakis, E., and Davies, A. M. (1999). Selective regulation of trkC expression by NT3 in the developing peripheral nervous system. J. Neurosci. 19, 6559-6570.

Yamamoto, M., Sobue, G., Yamamoto, K., Terao, S., and Mitsuma, T. (1996). Expression of mRNAs for neurotrophic factors (NGF, BDNF, NT3 , and GDNF) and their receptors (p75NGFR, trkA, trkB, and trkC) in the adult human peripheral nervous system and nonneural tissues. Neurochem. Res. 21, 929-938.

Yu, B., Zhou, S., Qian, T., Wang, Y., Ding, F., and Gu, X. (2011). Altered microRNA expression following sciatic nerve resection in dorsal root ganglia of rats. Acta Biochim. Biophys. Sin. (Shanghai) 43, 909-915.

Yu, B., Zhou, S., Wang, Y., Qian, T., Ding, G., Ding, F, et al (2012). miR-221 and miR-222 promote Schwann cell proliferation and migration by targeting LASS2 after sciatic nerve injury. J. Cell. Sci. 125, 2675-2683.

Yu, C. G., and Yezierski, R. P. (2005). Activation of the ERK1/2 signaling cascade by excitotoxic spinal cord injury. Brain Res. Mol. Brain Res. 138 244-255.

Yune, T. Y., Park, H. G., Lee, J. Y., and Oh, T. H. (2008). Estrogeninduced $\mathrm{Bcl}-2$ expression after spinal cord injury is mediated through phosphoinositide-3-kinase/Aktdependent CREB activation. J. Neurotrauma 25, 1121-1131.

Zhu, D. Y., Lau, L., Liu, S. H., Wei, J. S., and Lu, Y. M. (2004a). Activation of cAMP-response-element-binding protein (CREB) after focal cerebral ischemia stimulates neurogenesis in the adult dentate gyrus. Proc. Natl. Acad. Sci. U.S.A. 101, 9453-9457.

Zhu, W., Galoyan, S. M., Petruska, J. C., Oxford, G. S., and Mendell, L. M. (2004b). A developmental switch in acute sensitization of small dorsal root ganglion (DRG) neurons to capsaicin or noxious heating by NGF. J. Neurophysiol. 92, 3148-3152.

Zou, M., Li, S., Klein, W. H., and Xiang, M. (2012). Brn3a/Pou4f1 regulates dorsal root ganglion sensory neuron specification and axonal projection into the spinal cord. Dev. Biol. 364, 114-127.

Zvarova, K., Murray, E., and Vizzard, M. A. (2004). Changes in galanin immunoreactivity in rat lumbosacral spinal cord and dorsal root ganglia after spina cord injury. J. Comp. Neurol. 475, 590-603.

Conflict of Interest Statement: The authors declare that the research was conducted in the absence of any commercial or financial relationships that could be construed as a potential conflict of interest.

Received: 06 July 2012; accepted: 07 December 2012; published online: 09 January 2013.

Citation: Hougland MT, Harrison BJ, Magnuson DSK, Rouchka EC and Petruska JC (2013) The transcriptional response of neurotrophins and their tyrosine kinase receptors in lumbar sensorimotor circuits to spinal cord contusion is affected by injury severity and survival time. Front. Physio. 3:478. doi: 10.3389/fphys.2012.00478

This article was submitted to Frontiers in Integrative Physiology, a specialty of Frontiers in Physiology.

Copyright (c) 2013 Hougland, Harrison, Magnuson, Rouchka and Petruska. This is an open-access article distributed under the terms of the Creative Commons Attribution License, which permits use, distribution and reproduction in other forums, provided the original authors and source are credited and subject to any copyright notices concerning any third-party graphics etc. 